\title{
Mixed CFD-1D wind turbine diffuser design optimization
}

\author{
F. Sorribes-Palmer*, A. Sanz-Andres, L. Ayuso, R. Sant, S. Franchini \\ IDR/UPM, E.T.S.I. Aeronáutica y del Espacio, Universidad Politécnica de Madrid, Pza. Cardenal Cisneros, 3, 28040 Madrid, Spain
}

\begin{abstract}
A B S T R A C T
A method to design a diffuser augmented wind turbine (DAWT) is proposed, using as a guiding point the optimal pressure drop at the turbine. The use of concepts and expressions derived from a 1D analytic model helped to reduce the number of computational fluid dynamics simulations needed to find the optimal configuration. The proposed configuration can extract energy from the flow with the same efficiency as the state-of-the-art shrouded wind turbine (SWT) configurations but generating a significantly smaller wake, which makes this configuration a good candidate for wind farms or tidal applications. Furthermore, as a product of the 1D model, universal curves for the power coefficient have been obtained, as a function of the thrust coefficient, or disk loading, which have been compared with numerical and experimental results, showing a good agreement. Finally, the maximum ideal power coefficient has been found for a given configuration, which helps to estimate the margin for improvement of an actual design.
\end{abstract}

\section{Introduction}

In the last years, electricity generation costs have been decreasing, and in the best wind farms locations wind energy technologies are already competitive with regard to conventional power generation technologies Blanco [1], Neij [2], Goudarzi and Zhu [3]. In this context of rapid technological changes, wind farms become soon obsolete, providing an incentive to replace the existing wind farms soon by more efficient ones. Repowering a wind farm is the process of replacing existing wind turbines with new turbines that either have a larger nameplate capacity or more efficiency, resulting in a net increase of power generation [4].

Energy extraction from low wind energy density flows, as it can be in urban sites, has also lead the wind turbine industry to develop configurations to adapt to different environments, improve efficiency, and reduce costs [5]. Thus, different concepts have been developed to enhance efficiency of wind turbines in regions with less wind energy density. One of the approaches to increase the efficiency that has been devised is the diffuser augmented wind turbine (DAWT), which increases both the mass flow through the rotor section and the trust coefficient [6]. This concept has been explored by a remarkable number of researchers [7-10]. The theoretical performance enhancements of these devices are only achieved when the duct is sufficiently aligned with the wind, and the flow is no too gusty. This drawback, and other aerodynamic phenomena related to wind turbines, is studied by Sørensen [11], where different models to predict aerodynamic forces, design of rotor-blade airfoils, analysis of wind farms, and wind turbine wake simulations, are also considered.

One important point concerning shrouded wind turbines is the size of the wake, which can give rise to wake interference, which can cause fatigue loading of downwind turbines and also reduce the efficiency of wind farms. These are some of the reasons why wind turbine wake structure has been studied extensively [11-13].

Turbines installed inside small shrouded inlets are also used to deliver power to wireless sensors in pipes and ducts as shown in Howey et al. [14]. In this paper, the design of a turbine of $3.2 \mathrm{~cm}$ outer diameter that delivers between $80 \mu \mathrm{W}$ and $2.5 \mathrm{~mW}$ of electrical power at an air speed in the $3-7 \mathrm{~m} / \mathrm{s}$ range is presented.

Another approach is the so-called wind-lenses or shrouded wind turbine (SWT), which use a large flange attached at the exit of the diffuser shroud, thus increasing the low pressure region behind the rotor, due to the strong vortex wake formation behind the flange. This region helps to drawn a huge amount of mass flow inside the shrouded diffuser, thus accelerating the flow passing through the rotor. The flow around flanged diffusers has been studied experimentally and numerically by several researchers [15-18].

Concerning the diffuser, as a result of their numerical simulations and wind tunnel experiments, optimal open angles between 


\begin{tabular}{|c|c|c|c|}
\hline \multicolumn{2}{|c|}{ Nomenclature } & $k_{p c}$ & total pressure loss coefficient in the turbine, referred to \\
\hline \multicolumn{2}{|c|}{ Acronyms } & $K_{p d}$ & $\begin{array}{l}\text { total pressure loss coefficient in the duct, referred to } \\
\text { the exit speed }\end{array}$ \\
\hline CFD & computational fluid dynamics & $k_{p d}$ & total pressure loss coefficient in the duct, referred to \\
\hline $\begin{array}{l}\text { DAWI } \\
\text { SWT }\end{array}$ & $\begin{array}{l}\text { arfuser augmented wind turbine } \\
\text { shrouded wind turbine }\end{array}$ & $p_{e x}$ & $\begin{array}{l}\text { the turbine section speed } \\
\text { static pressure at the diffuser exit }\end{array}$ \\
\hline Greek $s$ & mbols & $p_{\infty}$ & static pressure of the undisturbed flow upstream \\
\hline$\delta$ & perturbation of $c_{p e x}$ around $c_{p e x}$, slope of $c_{p e x}\left(K_{p c}\right)$ & $r_{C T}$ & thrust coefficient ratio \\
\hline$\Delta K_{p c}$ & perturbation of $K_{p c}$ around $K_{p c \max 0}$ & $r_{K}$ & total pressure loss coefficient ratio, disk loading ratio \\
\hline$\Delta p_{c}$ & total pressure loss at the turbine section & $\operatorname{Re}$ & Reynolds number \\
\hline$\Delta p_{d}$ & total pressure loss at the diffuser & $r_{W_{0}}$ & augmentation ratio, referred to Betz limit \\
\hline & diffuser expansion area ratio $A_{e x} / A_{c}$ & $\begin{array}{l}U_{c} \\
U_{e x}\end{array}$ & $\begin{array}{l}\text { flow speed at the turbine section } \\
\text { flow speed at the exit section }\end{array}$ \\
\hline Roman & $y$ mbols & $U_{\infty}$ & flow speed upstream \\
\hline $\begin{array}{l}A_{c} \\
A_{e x}\end{array}$ & $\begin{array}{l}\text { turbine cross-section area } \\
\text { diffuser exit cross-section area }\end{array}$ & $W_{c}$ & power extracted from the flow by a turbine \\
\hline & capture area limit & & \\
\hline$C_{T}$ & thrust coefficient & Betz & Betz limit \\
\hline$C_{W c}$ & $\begin{array}{l}\text { extracted power coefficient referred to the turbine } \\
\text { section area } A_{c} \text { (same as } C_{p} \text { ) }\end{array}$ & $c$ & $\begin{array}{l}\text { turbine section } \\
\text { diffuser exit section }\end{array}$ \\
\hline$C_{\text {Wex }}$ & $\begin{array}{l}\text { extracted power coefficient referred to the exit cross } \\
\text { section area } A_{e x}\end{array}$ & $i$ & $\begin{array}{l}\text { ideal } \\
\text { maximum value }\end{array}$ \\
\hline$c_{\text {pex }}$ & pressure coefficient at the diffuser exit section & $\max$ & real \\
\hline K & $\begin{array}{l}\text { net total pressure loss coefficient, referred to the exit } \\
\text { speed }\end{array}$ & 0 & case $\delta=0$ \\
\hline$K_{p c}$ & $\begin{array}{l}\text { total pressure loss coefficient in the turbine, referred to } \\
\text { the exit speed }\end{array}$ & & \\
\hline
\end{tabular}

$10^{\circ}$ and $12^{\circ}$ are suggested in Chaker et al. [18] for flow at Reynolds number of 66500 (referred to the diffuser inlet section), for an empty diffuser and for a diffuser shrouding a small wind turbine, respectively. For larger half cone angles (included angles), a recirculation zone appears at the diffuser inner wall due to boundary layer separation, leading to large pressure losses in the diffuser.

Shrouded wind turbine flow fields are examined by Aranake et al. [19] who investigated several points: regions with flow separation, the development of velocity profiles, and the interaction between the turbine wake and shroud boundary layer, including the sensitivity of the solutions to blade rotation rate.

The possibility of using a shrouded diffuser with a curved flange at the exit in a vehicle is explored both numerically and experimentally by Chang et al. [20], reaching a factor of wind speed acceleration of 2.1 and a power output 3 times the one of the bare wind turbine. A similar diffuser augmented tidal turbine (DATT) is studied by simulation and validated with experiments by Shi et al. [21] for the propulsion of an autonomous underwater vehicle, doubling the power coefficient of the turbine without diffuser, achieving a maximum power coefficient of 0.83 with an optimal diffuser.

The impact of the diffuser augmentation on the performance of a tidal stream turbine under yawed flows is studied by Cresswell et al. [22]. The design allows the turbine performance to be maintained up to $\pm 30^{\circ}$ yaw angles. One of the conclusions of this work is that diffuser augmented turbines are less well suited to array deployment than are bare rotors, unless additional measures are taken to reduce wake interference or promote wake mixing. This conclusion points out the relevance of reducing turbine wake crosssection in order to reduce the distance between these devices in the case of considering their use to implement a wind farm.

The design of a duct and a rotor of a current streamlined marine turbine to optimize the efficiency over the largest operating range is carried out by Luquet et al. [23]. Two coupled generators are considered, which can rotate around a vertical axis fixed on the seafloor to get orientated with the flow. Different duct concepts are analyzed numerically; the maximum flow acceleration factor of the current velocity achieved is 1.4 . The numerical models of the two more relevant duct shapes are validate with experimental tests.

A numerical investigation on different shrouded wind turbines approaches, flanged and double diffusers with double cone shape splitter, is presented in Kannan et al. [24]. The turbine achieves a $61 \%$ wind speed velocity increase over a $4 \mathrm{~m} / \mathrm{s}$ free stream velocity using a diffuser of $16^{\circ}$ included angle, coupled with a $4^{\circ}$ splitter opening angle.

Flow separation in a diffuser, also called diffuser stall, is one of the main problems concerning power extraction. It depends on several parameters: diffuser inlet conditions, exit conditions, Reynolds number, Mach number, and diffuser geometry, as compiled in Blevins [25]. In this handbook, diffuser stall is studied for different configurations: two-dimensional, conical, annular, straight-walled, and curved wall diffusers. Curves for different stall regimes (first appreciable, large transitory, fully developed, hysteresis zone, and jet flow) for different diffusers as a function of geometry parameters are presented. Also the design principles followed in literature for two-dimensional diffusers with short vanes are summarized.

A multi-element diffuser is analyzed by Hjort and Larsen $[26,27]$, employing a passive boundary-layer stall control, which exceeds the Betz limit by $50 \%$. Besides energy augmentation, the diffuser helps shield the aero-acoustic noise propagation, and provides visual encapsulation of the rotating rotor. Design of a low tip-speed-ratio rotor for a new multi-element DAWT will lead to a very silent application.

The vortex shedding in a flanged diffuser, as the one proposed 
by Abe et al. [16], Chaker et al. [18], can lead to fatigue problems in the support structure which should be considered in the design. Wind tunnel experiments were conducted Wang et al. [28] to investigate the effects of a flanged diffuser on the dynamic behavior of the blade at different yaw angles (0-degree to 30-degree). Measurements of the dynamic strains of the rotating blades were performed to demonstrate that the blades can withstand both the ultimate loads and the fatigue loads to which the blade is expected to be subjected during its designed service life. The increase of the rotational speed of the blade in the case of a DAWT or wind-lens leads to the increase of centrifugal force acting on the blade, which should be considered in the structure design of the blade of the wind turbine. However, if wind lenses or DAWTs are employed to improve the low performance typical of low energy density flows, and for the dimensions of the wind turbines which are studied in the present paper, these aerodynamic loads should not be larger than for a bare wind turbine placed in a typical energy density wind flow.

In DAWT design, one of the main problems is diffuser design and optimization. It can be done by using a CFD tool, in order to predict flow detachment, pressure losses and pressure at the exit. This is the way followed by the authors above mentioned (Hansen et al. [6], Shives and Crawford [8], Hjort and Larsen [27] etc). The difficulty in the design comes from two places: first, there are several parameters involved in the problem whose influence should be known, at least qualitatively, and second, a guide for the design evolution is needed in order to get to the maximum performance.

Both problems can be faced if a suitable analytical simplified model is available, and validated. In this direction the main goal of this paper is to develop a semiempirical method: a 1D analytic model supported on CFD results (to calculate the unknown parameters of the 1D model) to design a DAWT (for water or air flows) of optimum extractable power, and with a minimum wake cross section area, applying the intake theory to a turbine inside a duct $[29,30]$. The analysis of this semiempirical model helps to identify the main parameters involved in the problem, and to understand their role. One example is the determination of the configuration that gives maximum power coefficient, and the influence of the key parameters, as well as the size of the wake generated by the diffuser. In Section 2, the influence of the total pressure losses inside the turbine on the efficiency of a DAWT at small wind speeds is analyzed. Intake theory results $[30]$ are applied to the DAWT configuration to find the maximum energy extraction. In Section 3 , the results of CFD numerical simulations performed of different configurations to find the maximum extractable power are presented. The aim of the design is to search for the maximum open angle without flow separation inside the diffuser, to reduce both the length of the duct and the wake cross section area, thus reducing the impact of the device. The problem is to avoid boundary-layer detachment in the very strong adverse pressure gradients that appear in DAWT diffusers [31]. Finally, in Section 4 results are summarized and conclusions are drawn.

\section{Mathematical model}

The configuration studied is shown in Fig. 1. A wind or water turbine is placed in the neck section " $\mathrm{c}$ " of a duct; the flow enters the duct through an inlet (or intake) at the input section " 1 ". It can be similar to the inlets used in the jet engines of the modern transport aircrafts, but in some cases special designs can be required. The flow at undisturbed conditions, $U_{\infty}$, is accelerated at the capture stream tube and at the inlet, passes through the turbine, and is decelerated in the diffuser, until it reaches the outer flow static pressure at the exit section "ex".

The accelerated flow speed at the turbine, $U_{c}$, increases the power extracted by the turbine, compared to a bare turbine.

The energy conservation equation, for a steady, incompressible flow [29] is given by

$p_{\infty}+\frac{1}{2} \rho U_{\infty}^{2}=p_{e x}+\frac{1}{2} \rho U_{e x}^{2}+\Delta p_{c}+\Delta p_{d}$,

where $p_{\infty}$ and $p_{e x}$ are the static pressure of the undisturbed flow upstream and at the exit, respectively; $\Delta p_{c}, \Delta p_{d}$ are the total pressure losses in the turbine and the duct, respectively; $U_{\infty}$ and $U_{e x}$ are the flow speed upstream and at the exit, respectively.

Eq. (2.1) can be written as

$\left(\frac{U_{e x}}{U_{\infty}}\right)^{2}+c_{\text {pex }}-1+\frac{\Delta p_{c}}{\frac{1}{2} \rho U_{\infty}^{2}}+\frac{\Delta p_{d}}{\frac{1}{2} \rho U_{\infty}^{2}}=0$,

where the pressure coefficient at the diffuser exit is $c_{p e x}=p_{e x} \frac{-p_{\infty}}{\frac{1}{2} \rho U_{\infty}^{2}}$. The total pressure losses in the turbine, $\Delta p_{c}$, and in the duct (mainly located in the diffuser), $\Delta p_{d}$, can be modeled as

$\Delta p_{c}=k_{p c} \frac{1}{2} \rho U_{c}^{2}, \quad \Delta p_{d}=k_{p d} \frac{1}{2} \rho U_{c}^{2}$,

where $k_{p c}$ and $k_{p d}$ are the total pressure loss coefficient in the turbine and in the duct (both inlet and diffuser) respectively, which in a first approach are supposed to be independent of $U_{c}$, the flow speed at the turbine section. The turbine is modeled as a pressure loss localized at the throat section. The total pressure loss in the diffuser $k_{p d}$ can be estimated from bibliography [32]. The exit pressure coefficient $c_{\text {pex }}$ depends on both the geometry of the diffuser and the flow rate, and is considered constant as a first approximation, but finally it will be necessary to consider its variation to take into account CFD simulations results. Introducing Eq. (2.3), and the conservation of mass between the turbine section $A_{C}$ and the exit section $A_{e x}\left(A_{c} U_{c}=A_{e x} U_{e x}\right)$ in Eq. (2.2) we obtain

$$
\begin{aligned}
\left(\frac{U_{e x}}{U_{\infty}}\right)^{2} & =1-c_{p e x}-\frac{\Delta p_{c}+\Delta p_{d}}{\frac{1}{2} \rho U_{\infty}^{2}} \\
& =1-c_{p e x}-\left(\frac{A_{e x}}{A_{c}}\right)^{2}\left(\frac{U_{e x}}{U_{\infty}}\right)^{2}\left(k_{p c}+k_{p d}\right) .
\end{aligned}
$$

From Eq. (2.4) the expression for the capture area $A_{\infty}$ is obtained

$$
\begin{aligned}
\frac{A_{\infty}}{A_{e x}} & =\frac{U_{e x}}{U_{\infty}}=\sqrt{\frac{1-c_{p e x}}{1+\left(k_{p c}+k_{p d}\right)\left(\frac{A_{e x}}{A_{c}}\right)^{2}}}=\sqrt{\frac{1-c_{p e x}}{1+\left(k_{p c}+k_{p d}\right) \mu^{2}}} \\
& =\sqrt{\frac{1-c_{p e x}}{1+K_{p c}+K_{p d}}} .
\end{aligned}
$$

where $\mu=\left(\frac{A_{\text {ex }}}{A_{c}}\right)$ is the expansion area ratio, which has been used

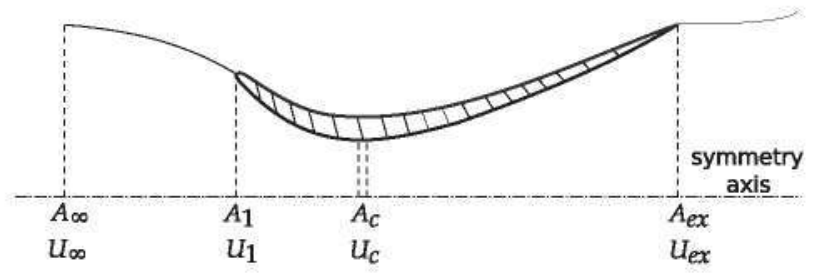

Fig. 1. Schematic geometry definition and nomenclature. 
to rewritten the pressure loss coefficients referred to the exit velocity, $K_{p c}=k_{p c} \mu^{2}$ and $K_{p d}=k_{p d} \mu^{2}$, respectively.

It should be pointed out that the inlet capture area $A_{\infty}$ becomes independent of the exit area $A_{e x}$ when the total pressure drop coefficient $k_{p c}+k_{p d}$ or area ratio $\mu$ are high enough, $A_{\infty} \simeq A_{\infty l}$, obtained from Eq. (2.5)

$$
\begin{aligned}
\frac{A_{\infty} l}{A_{e x}} & =\sqrt{\frac{1-c_{p e x}}{K_{p c}+K_{p d}}}=\frac{1}{\mu} \sqrt{\frac{1-c_{p e x}}{k_{p c}+k_{p d}}}=\frac{A_{c}}{A_{e x}} \sqrt{\frac{1-c_{p e x}}{k_{p c}+k_{p d}}}, \quad A_{\infty} \\
& =A_{c} \sqrt{\frac{1-c_{p e x}}{k_{p c}+k_{p d}}}
\end{aligned}
$$

which implies that the maximum capture area $A_{\infty}=A_{\infty l}$ is limited by the total pressure losses, that defines a limit to the volumetric flow through the duct and the turbine (see Fig. 2). Large duct pressure losses can be produced by diffuser stall. From Eq. (2.5), in the case of absence of pressure losses $\left(k_{p c}=k_{p d}=0\right)$ and $c_{p e x}=0$, it can be deduced that $A_{\infty}=A_{e x}$, thus the capture area is the same as the exit area. Therefore, hypothetically, the amount of flow through the duct can be increased without limit just by increasing $A_{e x}$. If $c_{p e x}$ $<0$ the capture area $A_{\infty}$ can be even larger than the diffuser exit area $A_{e x}$, thus increasing the flow through the duct. As shown in Fig. 2, the effect of pressure losses $k_{p c}$ is to reduce the mass flow through the duct, establishing an asymptotic limit for the capture area $A_{\infty l}$, independent of the exit area value $A_{e x}$, but it is proportional to the turbine area $A_{c}$. Outside this limit, the exit area $A_{e x}$ is one of the relevant parameters of the configuration, as it determines the maximum mass flow through the turbine, and also the area of the wind turbine wake, which ultimately represents the true cross-section area of the downstream flow really affected by the turbine perturbation. The study of its influence allows to understand the behavior of DWAT.

Eq. (2.5) can be rewritten as

$$
\frac{A_{\infty}}{A_{\infty} l}=\frac{1}{\sqrt{1+\frac{1}{K_{p c}+K_{p d}}}}=\frac{1}{\sqrt{1+\frac{1}{K}}}
$$

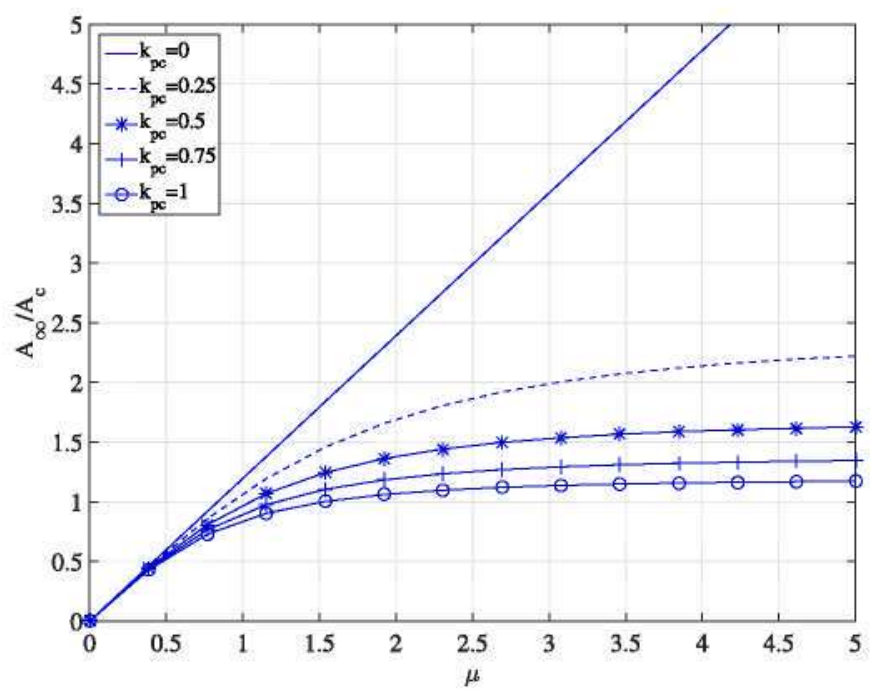

Fig. 2. Variation of the capture area $A_{\infty}$ to the turbine area $A_{c}$ ratio as a function of the expansion area ratio $\mu$ for different values of turbine pressure losses $k_{p c}$ (with $k_{p d}=0$ and $c_{\text {pex }}=-0.43$ ) from Eq. (2.5). Adapted from Seddon and Goldsmith [30]. where $K=K_{p c}+K_{p d}$ is the net total pressure loss of the DAWT referred to the exit speed $U_{e x}$. For large values of $K$ it can be simplified as

$$
\frac{A_{\infty}}{A_{\infty} l} \simeq \frac{1}{1+\frac{1}{2 K}} \simeq 1-\frac{1}{2 K}, \quad A_{\infty} \simeq A_{\infty l}\left(1-\frac{1}{2 K}\right)
$$

so that the increment $1 / 2 K$ give us an idea of how far the capture area $A_{\infty}$ is from the limit $A_{\infty}$.

Some experimental results on the dynamic pressure induced upstream of a screen simulating the turbine have been reported by Refs. [31,33]. To compare them with the results from the 1D model (see Section 3 Fig. 8), the dynamic pressure ratio $q_{c} / q_{\infty}$ can be obtained by using Eq. (2.5) as follows

$$
\begin{aligned}
\frac{q_{c}}{q_{\infty}} & =\left(\frac{U_{c}}{U_{\infty}}\right)^{2}=\left(\frac{U_{c}}{U_{e x}} \frac{U_{e x}}{U_{\infty}}\right)^{2}=\mu^{2} \frac{1-c_{p e x}}{1+\left(k_{p d}+k_{p c}\right) \mu^{2}} \\
& =\mu^{2} \frac{1-c_{p e x}}{1+K_{p d}+K_{p c}} .
\end{aligned}
$$

Information about the pressure losses in the diffuser $k_{p d}$ can be obtained by using Eq. (2.9) to predict the dynamic pressure ratio $q_{c}$ $/ q_{\infty}$, and comparing these results with experimental results. Another interesting conclusion is that the dynamic pressure ratio is proportional to $\left(1-c_{p e x}\right)$, therefore the flow speed through the duct increases as $\sqrt{1}-c_{\text {pex }}$.

Both the extracted power $W_{c}$ and the pressure losses in the diffuser $\Delta p_{d}$ depend on the flow that passes through the duct, which is controlled by the turbine pressure loss.

The power extracted from the flow by a turbine, $W_{c}$, is proportional to the product of the pressure loss across it, $\Delta p_{c}$, and the volumetric flow $Q=A_{\infty} U_{\infty}$

$$
\begin{aligned}
W_{c} & =Q \Delta p_{c}=A_{\infty} U_{\infty} k_{p c} \frac{1}{2} \rho U_{c}^{2}=\frac{1}{2} \rho U_{\infty}^{3}\left(\frac{A_{\infty}}{A_{e x}}\right)^{3}\left(\frac{A_{e x}}{A_{c}}\right)^{2} A_{e x} k_{p c} \\
& =\frac{1}{2} \rho U_{\infty}^{3}\left(\frac{1-c_{p e x}}{1+\left(k_{p c}+k_{p d}\right) \mu^{2}}\right)^{3 / 2} K_{p c} A_{e x} \\
& =\frac{1}{2} \rho U_{\infty}^{3} A_{e x} K_{p c}\left(\frac{1-c_{p e x}}{1+K_{p c}+K_{p d}}\right)^{3 / 2} .
\end{aligned}
$$

This parameter groups the energy extraction capacity of the turbine and the flow that passes through the turbine. In expression (2.10) the influence of the relevant parameters involved in the problem is considered, so that it can be used to perform an optimization analysis.

From Eq. (2.10) it can be deduced that the efficiency can be increased by making $c_{\text {pex }}$ as much negative as possible, which in general depends mainly on the external shape of the diffuser, but also on the internal flow and net pressure losses, $k_{p c}+k_{p d}$. Decreasing $c_{\text {pex }}$ is the way flanged diffusers (SWT) obtain larger efficiency. The extracted power coefficient referred to the exit area $A_{e x}, C_{W e x}$, depends only on two parameters, $c_{p e x}$ and $K_{p c}$, for a given diffuser

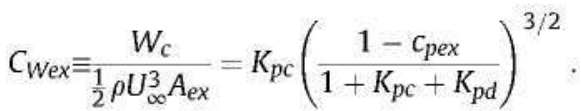

As an alternative to the reference area $A_{e x}$, the turbine section area $A_{c}$ could also be used, as is considered by other authors 
$[7,31,33]$; in this case the definition of the power coefficient would be

$C_{W c} \equiv \frac{W_{c}}{\frac{1}{2} \rho U_{\infty}^{3} A_{c}}=C_{W e x}\left(\frac{A_{e x}}{A_{c}}\right)=C_{W e x} \mu$.

As this change on reference area is just a proportionality factor, it does not influence the optimization analysis.

As it can be noted, the entrance area of the intake $A_{1}$ does not appear in the formulation of the problem. The intake duct should be designed in order to avoid flow detachment, thus avoiding additional pressure losses; in this sense, pressure losses in the entrance of a well-designed duct are negligible compared to pressure losses in the diffuser.

A maximum in the extracted power coefficient can be found under the assumption of $c_{p e x}$ being independent of $K_{p c}$, as a first approach to select the most appropriated turbine, which is the same as saying that the pressure at the exit will not be influenced by a change in the internal flow (the relation between these two parameters will be studied later on). Taking the derivative of $C_{W e x}$ in Eq. (2.11) with respect to $K_{p c}$, and equating to zero, the value of $K_{p c}$ that maximizes $C_{\text {Wex }}$ can be obtained

$K_{p c}=K_{p c \max 0}=2\left(1+K_{p d}\right)$,

which shows the relevance of parameter $K_{p c}$ concerning the design. A similar expression has also been obtained by Gilbert et al. [31] but this result is apparently neither discussed nor exploited by the authors. Recalling in its definition, to obtain the maximum extracted power $K_{p c}$ can be written as

$K_{p c \max 0}=2\left(1+K_{p d}\right)=2\left(1+k_{p d}\left(\frac{A_{e x}}{A_{c}}\right)^{2}\right)=\mu^{2} k_{p c}$,

and therefore

$\frac{A_{c}}{A_{e x}}=\sqrt{\frac{k_{p c}}{2}-k_{p d}}$,

which gives a relationship between the diffuser exit area $A_{e x}$, the turbine section area $A_{c}$, the turbine pressure loss $k_{p c}$, and the diffuser pressure losses $k_{p d}$, of the configuration that provides maximum power. If $A_{e x}$ is fixed, then this expression gives a relation between $A_{c}$ and $k_{p c}$ to select the most suitable turbine. If a turbine is selected, $A_{c}$ and $k_{p c}$ are given, then $A_{e x}$ can be determined according to the pressure losses in the diffuser $k_{p d}$.

In the optimization case being considered ( $c_{p e x}=c_{p e x 0}$ independent of $K_{p c}$ ) the position of the maximum extracted power $K_{p c \text { max } 0}$ does not depend on $c_{p e x 0}$, and the value of maximum power coefficient $C_{W e x \max }$ (introducing $K_{p c \max 0}$ from Eq. (2.14) in (2.11)) is given by

$C_{W e x \max }=\frac{2}{\sqrt{27}} \frac{\left(1-c_{\text {pex } 0}\right)^{3 / 2}}{\left(1+k_{p d} \mu^{2}\right)^{1 / 2}}=\sqrt{\frac{8}{27}} \frac{\left(1-c_{\text {pex } 0}\right)^{3 / 2}}{K_{p c \max 0}^{1 / 2}}$

The absolute maximum value of $C_{\text {Wex max }}$ is an ideal value which is achieved when $k_{p d}=0$, and is given by

$C_{\text {Wex } \max i}=2\left[\frac{1}{3}\left(1-c_{\text {pex } 0}\right)\right]^{3 / 2}$,

which clearly shows the relevance of the exit pressure coefficient.
Eqs. (2.16) and (2.17) can be used to explore the maximum ideal efficiency of DAWT configurations, compared to a bare turbine, whose limit was given by Betz, $C_{W c \text { Betz }}=16 / 27=0.593$, using the ratio of $C_{W e x \max }$ to Betz's limit, or augmentation ratio [31] $r_{W c}$ $=C_{W C} / C_{W C}$ Betz. The maximum ideal augmentation ratio $r_{W C \max i}$ is obtained from Eqs. (2.16) and (2).17) as follows

$$
\begin{aligned}
r_{\text {Wc } \max i} & =\frac{C_{\text {Wc max }}}{C_{\text {Wc Betz }}}=\frac{2 \mu}{16 / 27}\left[\frac{1}{3}\left(1-c_{\text {pex } 0}\right)\right]^{3 / 2} \\
& =\left(\frac{\sqrt{3}}{2}\right)^{3} \mu\left(1-c_{\text {pexo }}\right)^{3 / 2} \simeq 0.65 \mu\left(1-c_{\text {pex } 0}\right)^{3 / 2}
\end{aligned}
$$

$\mu$ and $c_{\text {pexo }}$ are not independent in a real design, instead they are related through the coupling between the internal and the external flows. Notwithstanding that, in Fig. 3 the ideal augmentation ratio is shown, using Eq. (2.18) considering $\mu$ and $c_{p e x 0}$ as independent, together with real values $r_{W_{C} \max r}$, and from several numerical and experimental optimized configurations (see (1)).

The vertical distance between ideal and real results in Fig. 3 gives an idea of the margin for improvement. According to Eq. (2.18) the maximum ideal augmentation ratio $r_{W c \max i}$ increases with both $\mu$ and $\left|c_{\text {pexo }}\right|$.

As can be deduced from Eq. (2.16) the maximum value of power coefficient decreases as the losses in the diffuser increase (see Fig. 4), which shows the relevance of reducing these losses in a practical design.

The result (2.11) can be cast in a universal curve using Eqs. (2.16) and (2).15) in the following way

$r_{W c} \equiv \frac{C_{\text {Wex }}}{C_{\text {Wex max }}}=\frac{\sqrt{27}}{2} \frac{K_{p c}\left(1+K_{p d}\right)^{1 / 2}}{\left(1+K_{p c}+K_{p d}\right)^{3 / 2}}=\sqrt{27} \frac{r_{K}}{\left(1+2 r_{K}\right)^{3 / 2}}$,

where $r_{K}=K_{p c} / K_{p c \max }$ is the pressure loss coefficient ratio (see

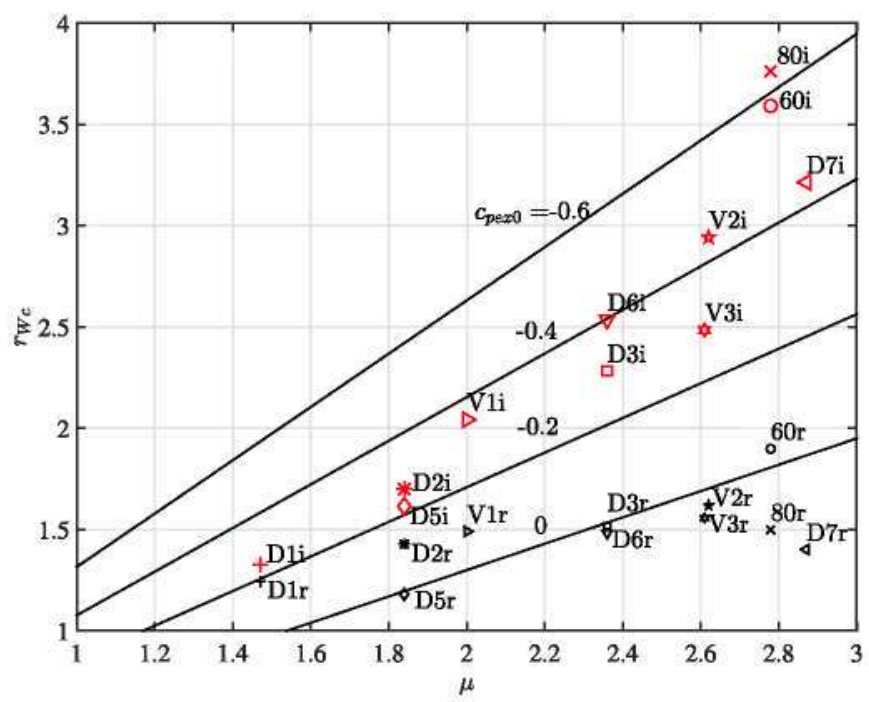

Fig. 3. Variation of the ideal and real maximum augmentation ratios $r_{W_{c} \max i}, r_{W c \max } r_{\text {. }}$ as a function of the expansion area ratio $\mu$, and the respective exit pressure coefficient $c_{\text {pex } 0}$. Coordinates of experimental or numerical results $\left(\mu, r_{W c}\right)$. r: real values; i: ideal values, same as real symbol, calculated using Eq. (2.18), with $\mu$ and $c_{\text {pexo }}$ values of the real case. Data points and symbol key can be found in Table 1. Solid lines: ideal results obtained from Eq. (2.18) with the value of $c_{\text {pexo }}$ given by the figures next to the lines. 


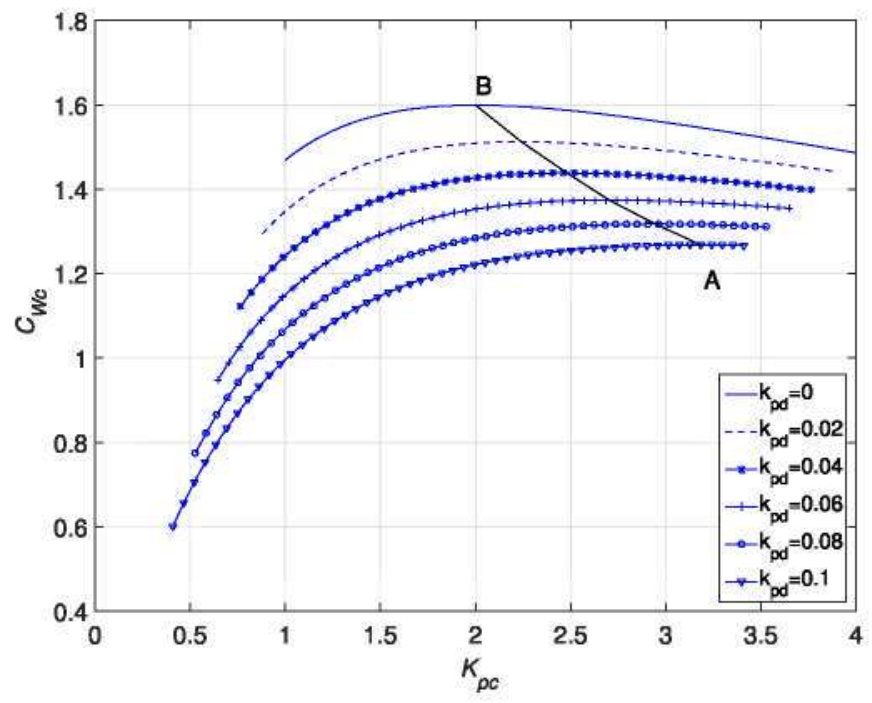

Fig. 4. Variation of the power coefficient $C_{W c}$ with the turbine pressure loss coefficient $K_{p c}$ for different values of $k_{p d}$ (with $\mu=2.4$ and $c_{p e x}=c_{p e x 0}=-0.43$ ). AB: locus of the maximum power coefficient.

Fig. 5). More discussions on this result can be found later on in this paper.

As shown in Figs. 10 and 11 of Gilbert et al. [31], $c_{\text {pex }}$ is almost independent of $\mu$ in the range of interest $(2<\mu<3.5)$ in a given configuration, but does depend on $k_{p c}$ (see Annex 1 ). In this case the condition that defines the maximum extracted power is obtained equating to zero the derivative of Eq. (2.11) that gives

$\frac{\mathrm{d} c_{p e x}}{\mathrm{~d} K_{p c}}=\frac{2}{3} \frac{\left(1-c_{p e x}\right)\left(1-\frac{K_{p c}}{2}+K_{p d}\right)}{K_{p c}\left(1+K_{p c}+K_{p d}\right)}$.

To achieve a practical result, the function $c_{p e x}\left(K_{p c}\right)$ can be approximated by a linear expression (the first term of the power expansion) such as

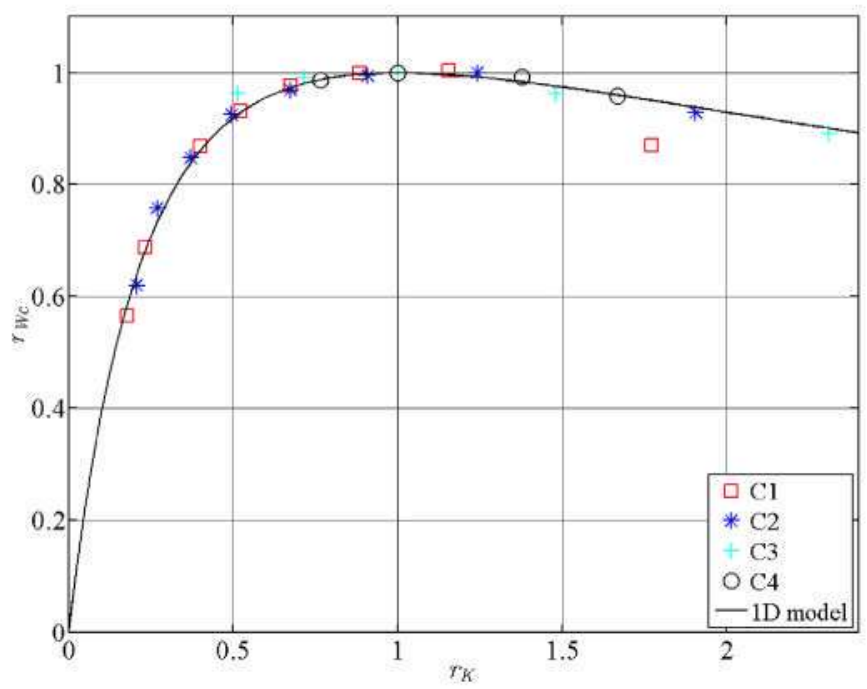

Fig. 5. Variation of the extracted power coefficient ratio $r_{W_{c}}$ as a function of pressure loss coefficient ratio $r_{K}$. (Eq. (2.19)). Numerical results from CFD model C1 [16] (squares); $\mathrm{C} 2\left({ }^{*}\right) ; \mathrm{C} 3(+)$ and $\mathrm{C} 4$ (circles) results from Section 3. $c_{p e x}\left(K_{p c}\right)=c_{p e x 0}\left[1+\delta\left(K_{p c}-K_{p c 0}\right)\right]$,

where $c_{\text {pex } 0}=c_{\text {pex }}\left(K_{p c 0}\right)$ is the reference value, and $K_{p c 0}$ is the point around which the analysis is done, e.g. $K_{p c 0}=K_{p c \max 0}$. Assuming $\delta$ $\ll 1$, the new power coefficient maximum position $K_{p c} \max \delta$ can be found as a perturbation of the position $K_{p c} \max 0$, as follows

$K_{p c \max \hat{o}}=K_{p c \max 0}+\Delta K_{p c}=2\left(1+K_{p d}\right)+\Delta K_{p c}$,

where $\Delta K_{p c} \ll 1$ is the shift in the position of the maximum power coefficient due to $\delta$. Introducing Eqs. (2.21) and (2.22) in (2.20) and neglecting terms of order $\odot\left(\Delta K_{p c}^{2}\right)$ one obtains

$\Delta K_{p c} \cong 18 \delta \frac{-c_{\text {pex } 0}}{1-c_{\text {pex } 0}}\left(1+k_{p d} \mu^{2}\right)$,

which gives the shift of the maximum position $\Delta K_{p c}$ with regard to the configuration with constant pressure coefficient $c_{\text {pex }}=c_{\text {pexo }}$, although the value of the maximum itself $C_{W e x \max }$ does not vary much with $\Delta K_{p c}$ or $\delta$ (see Fig. 6).

In most cases the value of $c_{\text {pex }}$ slope is negative, $\delta<0$, and also $c_{\text {pex }}<0$ (see Annex 1), this results in $\Delta K_{p c}<0$, which implies that the maximum is shifted towards smaller values of $K_{p c}$ mac (moving to larger values of $\left.\left|c_{\text {pex }}\right|\right)$. The pressure loss gives rise to an increase of the position of the maximum $K_{p c \max }$ as shown in Fig. 4. The effect of varying $\delta$ in a diffuser duct without total pressure loss, $k_{p d}=0$, is shown in Fig. 6.

In a given configuration, both the diffuser total pressure losses $k_{p d}$ and the variation $\delta$ of the exit pressure coefficient should be taken into account simultaneously, so that the position of the maximum power coefficient $K_{p c \text { maxo }}$ depends on the relative strength of both effects. Whether $K_{\text {pcmax }}$ is smaller or larger than 2 , can be found using Eqs. (2.22) and (2.23), and one obtains that $K_{p c \max \delta}>2$ if

$\delta>-\frac{1}{9} \frac{K_{p d}}{\left(1+K_{p d}\right)} \frac{1-c_{p e x}}{-c_{p e x}} \equiv \delta^{*}$.

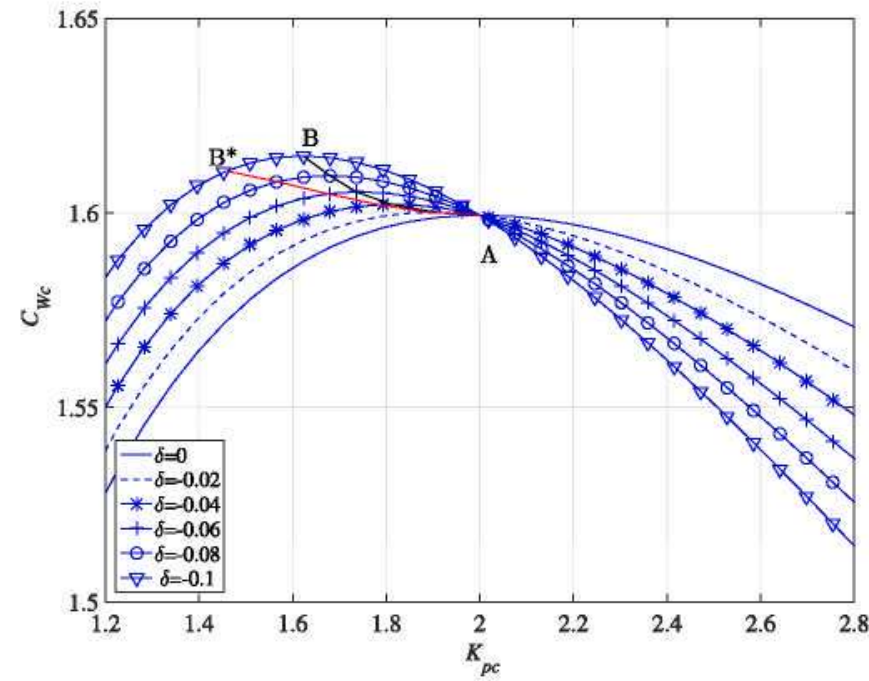

Fig. 6. Variation of the power coefficient $C_{W c}$ with the turbine pressure loss coefficient $K_{p c}$, for different values of $c_{\text {pex }}$ slope, $\delta$ (with $\mu=2.4, k_{p d}=0$ and $c_{\text {pexo }}=-0.43$ ). AB: locus of maximum power coefficient points. AB': locus given by Eq. (2.22), approximation to the maximum power coefficient. 
In the case $\delta=\delta^{*}$ both effects compensate each other and the maximum position remains the same, $K_{p c \max \delta}=2$.

Lawn [7] and Shives and Crawford [8] already studied the same DAWT problem, using as parameters the efficiency coefficients in the diffuser and in the entrance, instead of total pressure losses, with a notation that makes the analysis difficult, at least for the authors. In the opinion of the authors, the formulation based on the total pressure loss used in intake theory [29] is more convenient for the analysis. Obviously, the results obtained in both cases for the $C_{W c}$ are the same (see Eq. (13) from Lawn [7]). However, Lawn did not develop the study as has been done in the present paper, but only applies the theory of actuator disk to relate the speed at the exit with pressure loss in the turbine

$K_{L}=\frac{\Delta p_{c}}{\frac{1}{2} \rho U_{c}^{2}}$,

in his notation, which is the same coefficient $k_{p c}$ used here. Lawn's resistance coefficient $K$, is denoted here as $K_{L}$ to avoid confusion. In his analysis, Lawn considered the case in which $c_{p e x}=0$, and neglected the pressure losses in the diffuser, reaching the same result of Betz theory. But this is not applicable to the study of the shrouded turbine where there is no free streamlines. Furthermore, as he takes $c_{\text {pex }}=0$ the effect of the diffuser would be lost, while this is the principal advantage of DWAT, which allows to reach high negative values of $c_{p e x}$. Lawn considered the pressure losses as static pressure losses, instead of total pressure losses, which is the term commonly used in the literature. The parameters $K_{p c}=\mu^{2} k_{p c}$ and $K=K_{p c}+K_{p d}$ used here should not be confused with the notation used by Lawn $\left(K_{L} \equiv k_{p c}\right)$.

In order to compare the $1 \mathrm{D}$ model results with some of the numerical and experimental results in the literature, which use the thrust coefficient, $C_{T}$, it can be related to the parameters of the 1D model using Eq. (2.5), as follows

$$
\begin{aligned}
C_{T} \equiv \frac{\Delta p_{c} A_{c}}{\frac{1}{2} \rho U_{\infty}^{2} A_{c}} & =\frac{\Delta p_{c}}{\frac{1}{2} \rho U_{c}^{2}} \frac{U_{c}^{2}}{U_{\infty}^{2}}=k_{p c}\left(\frac{A_{\infty}}{A_{c}}\right)^{2}=k_{p c} \mu^{2}\left(\frac{A_{\infty}}{A_{e x}}\right)^{2} \\
& =K_{p c} \frac{1-c_{p e x}}{1+K_{p c}+K_{p d}} .
\end{aligned}
$$

The power coefficient $C_{W c}$ is denoted as $C_{P}$ in some papers $[21,27]$ and, according to the $1 \mathrm{D}$ model, can be obtained as a function of $C_{T}$ in the following way

$$
\begin{aligned}
C_{P} \equiv C_{W c} & =\frac{\Delta p_{c} A_{c} U_{c}}{\frac{1}{2} \rho U_{\infty}^{3} A_{c}}=C_{T} \frac{A_{\infty}}{A_{c}}=C_{T} \frac{A_{\infty}}{A_{e x}} \mu=\mu C_{T} \sqrt{\frac{C_{T}}{K_{p c}}} \\
& =\mu C_{T} \sqrt{\frac{1-C_{p e x}-C_{T}}{1+K_{p d}}},
\end{aligned}
$$

which shows the influence of $\mu$ and $k_{p d}$ in the $C_{P}\left(C_{T}\right)$ curve. Using Eq. (2.25) with (2.13) the value of $C_{T}$ that gives the maximum power coefficient (for $\delta=0$ ) can be determined

$C_{T \max 0}=\frac{2}{3}\left(1-c_{p e x 0}\right)$

which is independent of $K_{p d}$. Then, from Eq. (2.25) and using the thrust coefficient ratio $r_{C T}=C_{T} / C_{T \max 0}$ and the disk loading $r_{K}$ $=K_{p c} / K_{p c \max 0}$ one obtains
$\frac{C_{T}}{C_{T \max 0}}=3 \frac{K_{p c} / K_{p c \max 0}}{1+2 K_{p c} / K_{p c \max 0}}$,

therefore,

$r_{C T}=3 \frac{r_{K}}{1+2 r_{K}}$,

and alternatively

$r_{K}=\frac{r_{C T}}{3-2 r_{C T}}$

Eqs. (2.28) and (2.29) are also universal expressions for the relationship between the thrust coefficient ratio, $r_{C T}$, and the turbine total pressure loss coefficient ratio, $r_{K}$. By substitution of (2.29) in (2.19) one obtains a universal expression for the power coefficient ratio, as a function of the thrust coefficient ratio

$r_{W c}=r_{C T} \sqrt{3-2 r_{C T}}$.

The good agreement of this result with several numerical results can be shown in Fig. 7. The reference values to determine $r_{C T}, r_{K}, r_{W c}$ are $C_{T \max 0}, K_{p c \max 0}$ and $C_{W c \max 0}$ respectively, that can easily be determined from experimental or numerical results.

The maximum positions of both functions $C_{W c}\left(C_{T}\right)$ and $C_{W c}\left(K_{p c}\right.$ ) are $C_{T \max 0}$ and $K_{p c \max 0}$, respectively, and correspond to the same point $C_{T \max 0}=C_{T}\left(K_{p c \max 0}\right)$, because the variation $C_{T}\left(K_{p c}\right)$, given by Eq. (2.25), is monotonous.

According to Eq. (2.27), the maximum position $C_{T \max 0}$ depends only on $c_{p e x 0}$ and is independent of diffuser losses $K_{p d}$, as shown in numerical results [8]. In the case $\delta \neq 0$, the influence of this parameter should also be taken into account.

Once the position of the maximum power $C_{T \max 0}$ is obtained from experimental results, the value of $c_{\text {pex }}$ can be deduced from relation (2.27); and using Eqs. (2.16) and (2.26), the power coefficient can be evaluated at the maximum point $C_{T}=C_{T \text { max0 }}$ in the following way

$C_{W c \max }=\mu \frac{C_{T \max 0}^{3 / 2}}{K_{p c \max 0}^{1 / 2}}$.

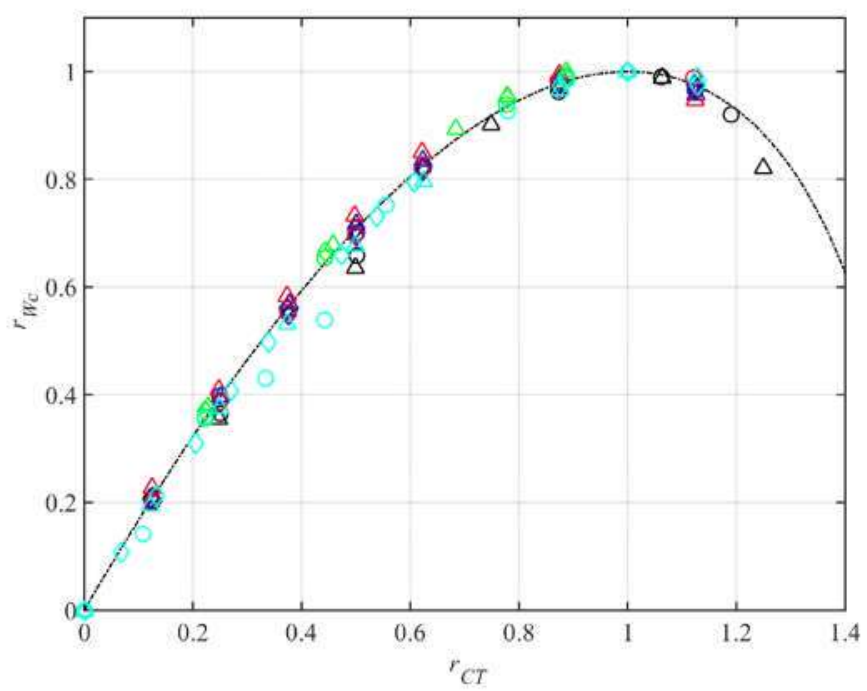

Fig. 7. Variation of the power coefficient ratio $r_{w c}$ as a function of the thrust coefficient ratio $r_{C T}$. Numerical results from Shives and Crawford [8] (curves D1, D2, D3, D5, D6, D7, D8, D9, D10, V1, V2, V3 in Figs. 8, 13 and 16). 


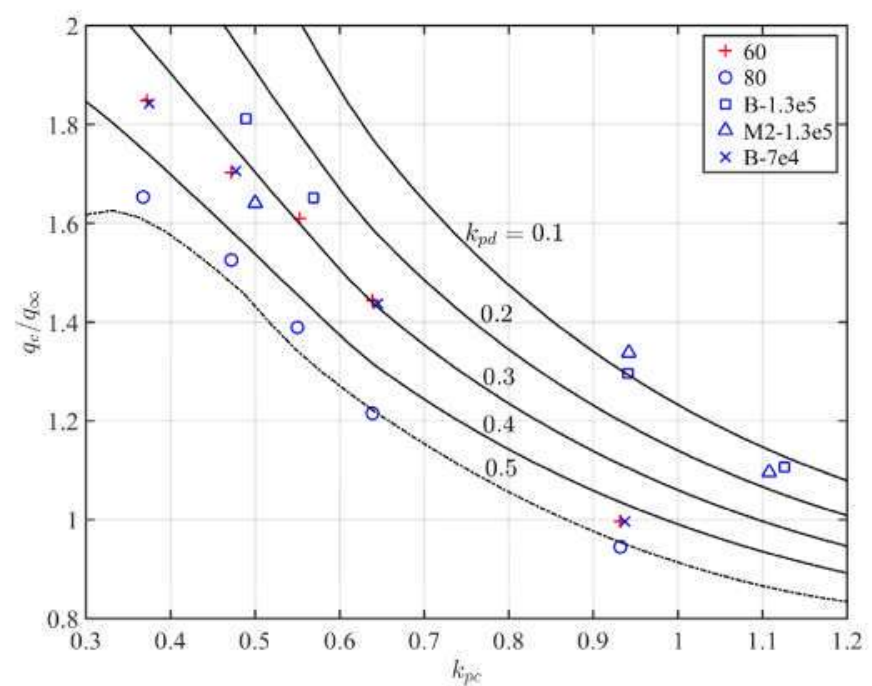

Fig. 8. Variation of the dynamic pressure ratio $q_{c} / q_{\infty}=\left(\frac{U_{c}}{U_{\infty}}\right)^{2}$ as a function of the turbine pressure loss coefficient $k_{p c}$. Solid line (dot-dashed line): 1D model results for $c_{p e x}\left(K_{p c}\right)$ of $60^{\circ}\left(80^{\circ}\right)$ diffuser. $k_{\text {pd }}$ : diffuser pressure loss coefficient. Experimental results from Gilbert et al. [31], Fig. $6, \mu=2.78$ for two diffusers: (o) $80^{\circ}$ diffuser; ( + ) $60^{\circ}$ diffuser. Experimental results from Foreman and Gilbert [33]. Fig. 6: (squares) B_1.3e5; (triangles) M2_1.3e5; (x) B_7e4; with the following key: B: baseline; M2: model 2; 1.3e5: Reynolds number $1.3 \cdot 10^{5}$.

Therefore, if both $C_{W c \max 0}$ and $C_{T \max 0}$ are obtained from experiments, $K_{p c \max 0}$ can be deduced from (2.31). Then, using (2.13) the pressure loss coefficient $k_{p d}$ can be obtained,

$k_{p d}=\frac{1}{2} \frac{C_{T \max 0}^{3}}{C_{W c \max }^{2}}-\frac{1}{\mu^{2}}$.

\subsection{Experimental validation}

The 1D model presented in the previous paragraphs has been validated by comparing the $1 \mathrm{D}$ model results with existing experimental and numerical results. In Figs. 5 and 7 the results concerning the universal curves $r_{W c}\left(r_{K}\right)$, Eq. (2.19) and $r_{W_{c}}\left(r_{C T}\right)$, Eq. (2.30), respectively, are plotted together with a number of both experimental and numerical results. The good agreement of these data with the $1 \mathrm{D}$ model results can be appreciated.

A detailed comparison has been made with the experimental results of Gilbert et al. [31] and Foreman and Gilbert [33]. The experimental results from Gilbert et al. [31], for the dynamic pressure ratio $q_{c} / q_{\infty}$ (Fig. 6 in Gilbert et al. [31]) as a function of the pressure jump in the turbine are shown in Fig. 8. The pressure jump coefficient is denoted as $C_{T}$ by Gilbert et al. [31], but in fact coincides with the definition of $k_{p c}$. These experimental results were obtained with two two-segment diffusers, with included angles $\theta$ $=60^{\circ}, \theta=80^{\circ}$, respectively. The results of the $1 \mathrm{D}$ model (Eq. (2.9)) are also plotted, for comparison.

It is shown that the experimental results seem to follow the trend marked by the two curves obtained from the 1D model for diffuser total pressure loss $k_{p d}=0.30$ and $k_{p d}=0.35$ in the case $\theta$ $=60^{\circ}$, and in the case $\theta=80^{\circ}$ the experimental results follow the curve $k_{p d}=0.45$ for $k_{p c}<0.6$, and the line $k_{p d}=0.5$ for $k_{p c}>0.6$.

To obtain the results from the 1D model, the variation $c_{p e x}\left(K_{p c}\right)$ has been taken into account for the cases $\theta=60^{\circ}$ and $\theta=80^{\circ}$, instead of using a constant value for $c_{\text {pex }}$. These data were obtained from the experimental results reported in Fig. 11 of Gilbert et al. [31]. In this way, the agreement between 1D model and experimental results significantly improves.

The pressure losses in both diffusers derived from the previous comparison ( $k_{p d}=0.30, k_{p d}=0.5$ ) are comparatively large with regard to a well-designed diffuser $\left(k_{p d} \sim 0.1\right)$. This fact suggests the possibility that some mechanism was present that produced an increase of $k_{p d}$, for instance, boundary layer detachment in a part of the diffuser walls, or a concentrated total pressure loss at the exit discharge, as it seems to happen in the case of some SWT and windlenses.

Some experimental results from Fig. 6 of Foreman and Gilbert [33] are also included in Fig. 8, which show similar behavior than those of Gilbert et al. [31].

The variation of $r_{W c}$ as a function of $k_{p c}$ according to 1D model is shown in Fig. 9, for several values of the diffuser pressure losses $k_{p d}$, together with the experimental results of Gilbert et al. [31] and Foreman and Gilbert [33]. The behavior is similar to that shown in Fig. 8. In the case of the diffuser with $\theta=60^{\circ}$, compared to the values predicted by the $1 \mathrm{D}$ model, the diffuser pressure losses of the measured points in the range $k_{p c}<0.65$ seems to be smaller than for larger values of $k_{p d}$.

In the case $\theta=80^{\circ}$ the agreement with experimental results of the $1 \mathrm{D}$ model prediction for $k_{p d}=0.45$ is good in the range $k_{p c}<0.6$, but in the range $k_{p c}>0.6$ the best fitting changes to the $1 \mathrm{D}$ prediction for $k_{p d}=0.5$, much as it is observed in Fig. 8 (Fig. 6 of Gilbert et al. [31]).

\section{Numerical simulations}

ANSYS Fluent ${ }^{10}$ (15.0 version) was used to simulate both the internal and external flow around the diffuser. This commercial software has been previously validated in literature for computations of complex turbulent flows, Kim et al. [34].

The characteristic velocity involved in this study was the appropriate one to obtain a Reynolds number of 250000 , as in the problems studied by Abe and Ohya [15], and Shives and Crawford [8]. The flow was considered as incompressible and the air

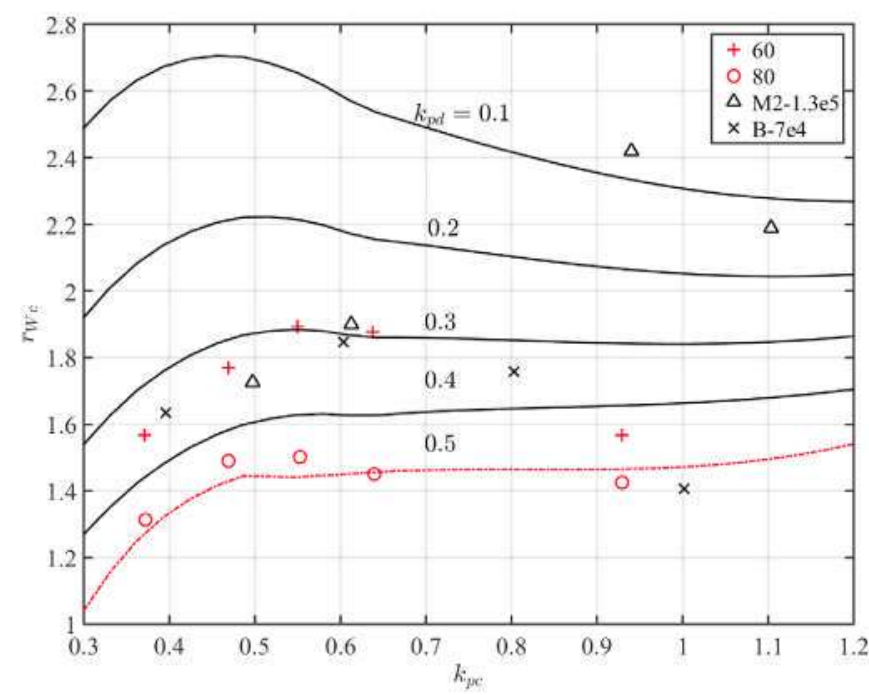

Fig. 9. Variation of the power coefficient ratio to Betz limit $r_{W c}$, as a function of the turbine pressure loss coefficient $k_{p c}$. Solid line (dot-dashed line) 1D model results for $c_{\text {pex }}\left(K_{p c}\right)$ of $60^{\circ}\left(80^{\circ}\right)$ diffuser. $k_{p d}$ : diffuser pressure loss coefficient. Experimental results from Gilbert et al. [31]. Fig. 6, $\mu=2.78$ for two diffusers: (o) $80^{\circ}$ diffuser; (+) $60^{\circ}$ diffuser. Experimental results from Foreman and Gilbert [33] Fig. 6: (triangles) M2_1.3e5; (x) B_7e4; with the following key: B: baseline; M2: model 2; 1.3e5: Reynolds number $1.3 \cdot 10^{5}$. 


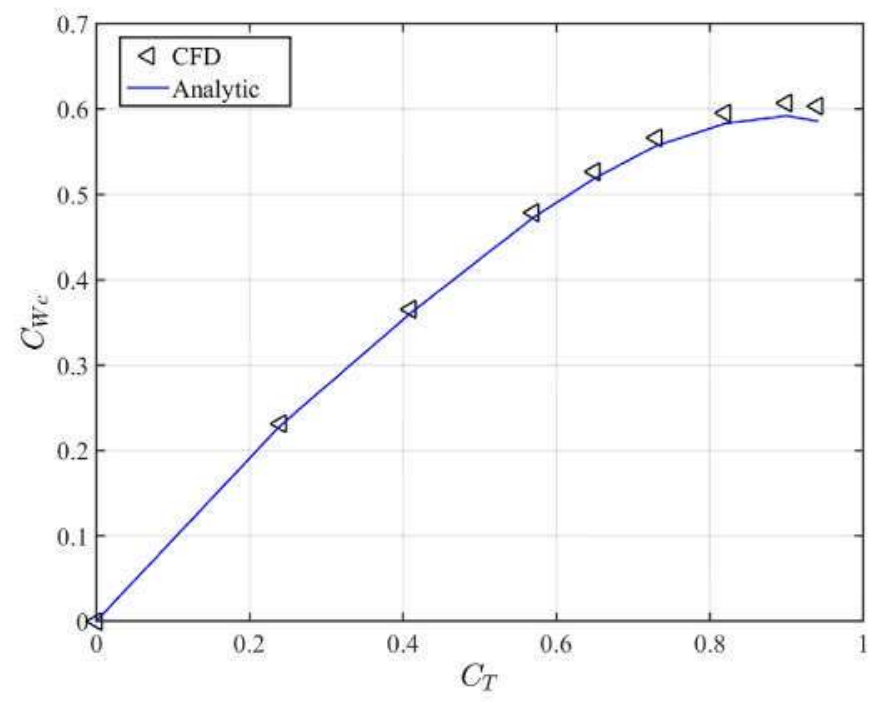

Fig. 10. CFD turbine model validation, variation of the power coefficient $C_{W c}$ as a function of the thrust coefficient $C_{T}$, for a bare turbine, with a hub.

properties were assumed to be constant. A pressure-based solver was used and the energy equation was ignored. Consequently, only continuity, moments and turbulence equations [35] were involved in the numerical study. In addition, the airflow was considered as steady and axisymmetric.

The numerical simulation was performed using the steady RANS equations. The realizable $k-\varepsilon$ model proposed by Shih et al. [36] was used for turbulence model. This model has been extensively validated for a wide range of flows [34-36], including rotating homogeneous shear flows, free flows including jets and mixing layers, channel and boundary layer flows, and separated flows. For all these cases, the performance of the model has been found to be substantially better than that of the standard $k-\varepsilon$ model. Especially noteworthy is the fact that the realizable $k-\varepsilon$ model resolves the round-jet anomaly; i.e., it predicts the spreading rate for axisymmetric jets as well as that for planar jets.

The coupling between the governing equations was made by means of the SIMPLE scheme, least squares cell based solver was used. A second order upwind difference scheme was used for spatial discretization. A velocity boundary was used at the inlet, and a static pressure boundary condition was used at the outlet. In addition, at the axis an axisymmetry boundary condition was considered. All of the walls were defined as non-slip boundaries. To

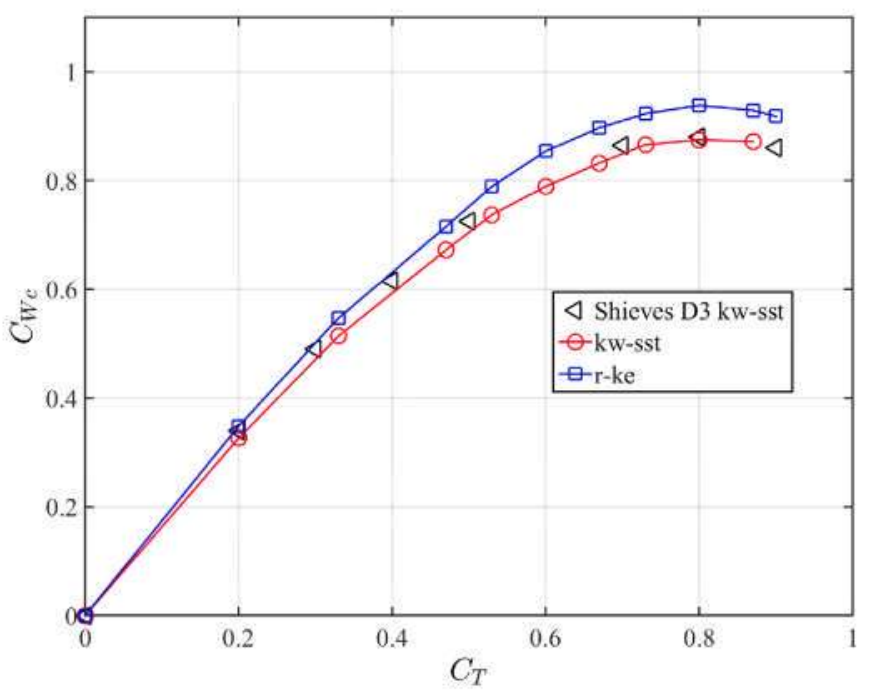

Fig. 12. Variation of the power coefficient $C_{W c}$ as a function of the thrust coefficient $C_{T}$ for two turbulence models ( $k-\omega s s t, r-k-\varepsilon$ ), compared to D3 duct type of Shives and Crawford [8].

validate the Fluent numerical model developed, an actuator disc simulating a bare turbine was studied. The results match what is expected for the theoretical result for the actuator disc [37] as shown in Fig. 10.

The grids used in this study were all regular orthogonal elements, and they were finer near the walls where large velocity gradients exist. The criteria used to position the nodes near the wall were that $y^{+}<1$ and that several nodes were located in the viscous sub-layer. A grid independence study was conducted by comparing the results of different grids [38]. The final grids used in this study contain up to 250000 cells. The type of mesh used is shown in Fig. 11 where both the baseline model mesh (defined in the following paragraph), and the mesh used by Shives and Crawford [8] are sketched.

The results obtained with the CFD model developed here are in good agreement with those obtained by Shives and Crawford [8] for the duct type D3, as shown in Fig. 12. In this figure, the results obtained for the duct type D3 using two turbulence models, realizable $k-\varepsilon$ and $k \omega-$ sst [39] are shown. Shives solves this case with the commercial software CFX 12 and turbulence model $k \omega-$ sst. As shown in this figure, results are very similar when the same turbulence model is used. It also shows that in this case the turbulence a)

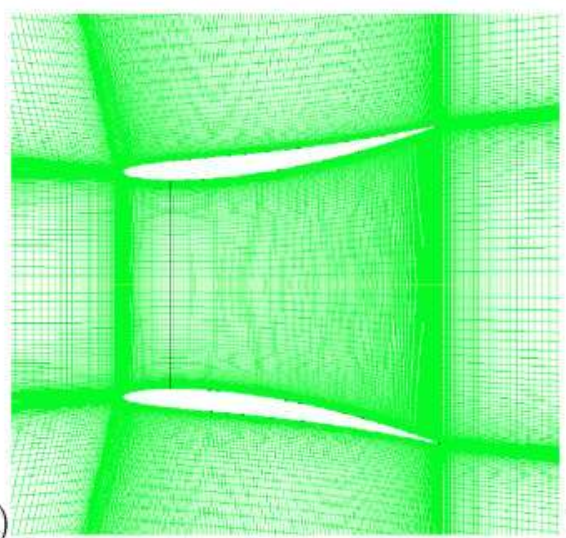

b)

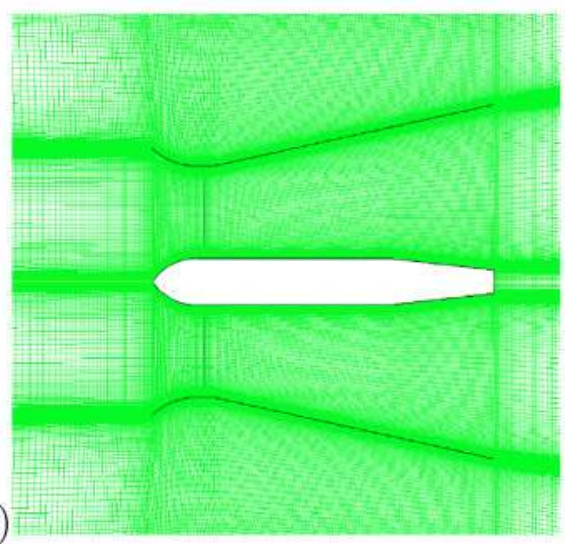

Fig. 11. Examples of surface mesh near the duct profile: a) Shives D3, b) Baseline model. 
model realizable $k-\varepsilon$ predicts a maximum power coefficient 7\% higher than calculated with the turbulence model $k \omega-s s t$, which can be due to the early detached flow in the diffuser walls, as predicted by this model.

From the 1D model developed in Section 2, expression (2.22) the turbine pressure loss for maximum power $K_{p c} \max$ was obtained, and was also deduced that to get maximum $C_{W e x}$ or $C_{W c}$ is necessary to make $c_{p e x}$ as much negative as possible, with $k_{p d}$ as small as possible. These conclusions are mentioned in the literature but not clearly derived and quantified and systematically employed. Our aim is to try to design a DWAT with a duct that meets these criteria.

Four types of diffusers have been studied numerically with CFD, all of them have the same length $2500 \mathrm{~mm}$ and included angle $\beta$ $=12, \mu=2.43$ and $A_{c}=3.02 \mathrm{~m}^{2}$ to compare with the design of Abe et al. [16]. These types are:

C1 A shrouded duct turbine design with a large flange proposed by Abe et al. [16] has been studied, to further validate the numerical model presented here (see Fig. 14).

C2 A baseline (1 segment) DWAT, the largest simple diffuser with maximum included angle, where a small flow detachment is already present (see Fig. 15).

C3 A simple configuration of 2 segments DWAT, where flow detachment is avoided by injecting energy into the boundary layer, to study the effect of the slot in $k_{p d}$ and $c_{\text {pexo }}$ (see Fig. 16). C4 An optimized diffuser (although as simple as possible) with an internal vane, designed to prevent flow from detachment inside the duct, and to achieve a smooth output flow (to minimize both pressure losses and wake area), including a Gurney flap (see Fig. 17) to increase $\left|c_{p e x}\right|$. This optimization has consisted on: modifying the position of the vane in the duct, and the distance to the diffuser.

Sketches of these mentioned configurations are presented in Fig. 13.
Table 1

Real ( $r$ ) and ideal (i) maximum augmentation ratio $r_{W C}$ for DAWT configurations.

\begin{tabular}{llllllll}
\hline Fig. $^{\mathrm{a}}$ & Curve code & $\mu$ & $c_{\text {pex } 0}$ & $C_{T \max }$ & $C_{\text {Wc max }}$ & $r_{W c \max r}$ & $r_{W c \max i}$ \\
\hline $7^{\mathrm{b}}$ & $60^{\mathrm{d}}$ & 2.78 & -0.580 & $0.60^{\mathrm{e}}$ & 1.127 & 1.90 & 3.59 \\
$7^{\mathrm{b}}$ & $80^{\mathrm{d}}$ & 2.78 & -0.630 & $0.52^{\mathrm{e}}$ & 0.890 & 1.50 & 3.76 \\
$13^{\mathrm{c}}$ & D1 & 1.47 & -0.246 & 0.800 & 0.736 & 1.24 & 1.33 \\
$13^{\mathrm{c}}$ & D2 & 1.84 & -0.265 & 0.801 & 0.848 & 1.43 & 1.70 \\
$13^{\mathrm{c}}$ & D3 & 2.36 & -0.303 & 0.802 & 0.901 & 1.52 & 2.28 \\
$13^{\mathrm{c}}$ & D5 & 1.84 & -0.221 & 0.803 & 0.699 & 1.18 & 1.61 \\
$13^{\mathrm{c}}$ & D6 & 2.36 & -0.398 & 0.802 & 0.808 & 1.48 & 2.54 \\
$13^{\mathrm{c}}$ & D7 & 2.87 & -0.437 & 0.887 & 0.830 & 1.40 & 3.21 \\
$16^{\mathrm{c}}$ & V1 & 2.00 & -0.352 & 0.797 & 0.883 & 1.49 & 2.04 \\
$16^{\mathrm{c}}$ & V2 & 2.62 & -0.440 & 0.898 & 0.961 & 1.62 & 2.94 \\
$16^{\mathrm{c}}$ & V3 & 2.61 & -0.290 & 0.795 & 0.923 & 1.56 & 2.49 \\
\hline
\end{tabular}

a Source of data.

b Gilbert et al. [31].

c Shives and Crawford [8].

d Included angle, in degrees.

${ }^{e}$ In this case is $k_{p c \max }$ instead of $C_{T \max }$.

Table 2

Pressure loss coefficient in the diffuser $k_{\text {pd }}$ for the different DWAT configurations. CFD: results from CFD; $1 \mathrm{D}$ : value to use in the $1 \mathrm{D}$ model that better fits the power coefficient curves to the CFD results.

\begin{tabular}{lllll}
\hline$k_{p d}$ & $\mathrm{C} 1$ & $\mathrm{C} 2$ & $\mathrm{C} 3$ & $\mathrm{C} 4$ \\
\hline CFD & 0.078 & 0.063 & 0.031 & 0.104 \\
1D & 0.109 & 0.088 & 0.044 & 0.104 \\
\hline
\end{tabular}

These CFD studies allowed us also to obtain the variation of $c_{p e x}$ $\left(K_{p c}\right)$, which could not be obtained analytically, and has been used to feed the $1 \mathrm{D}$ model. Using this mixed semiempirical model, power coefficients have been obtained and compared to those calculated directly from CFD. The results are shown in Fig. 18.

The power variation curves $C_{W c}\left(K_{p c}\right)$ obtained from CFD and those obtained from 1D model Eq. (2.11) are very similar, if in the 1D model the variation of the pressure coefficient $c_{p e x}\left(K_{p c}\right)$
C1)

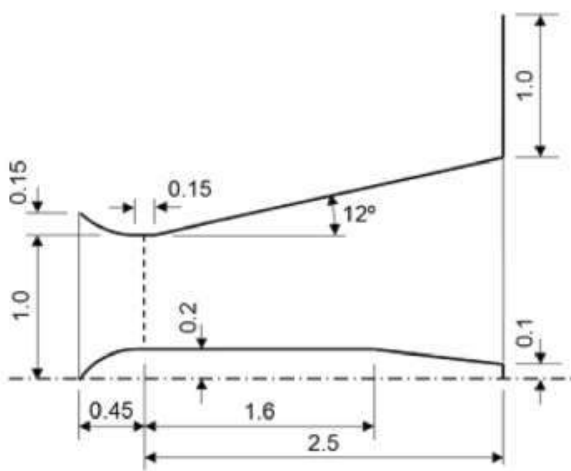

C2)

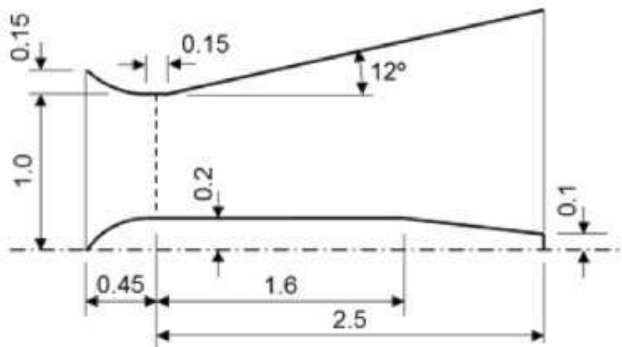

C3)

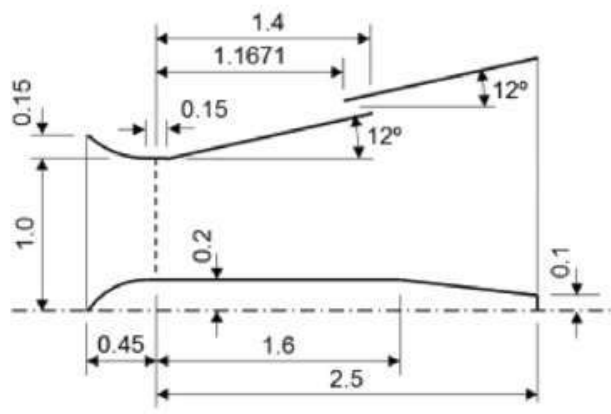

C4)

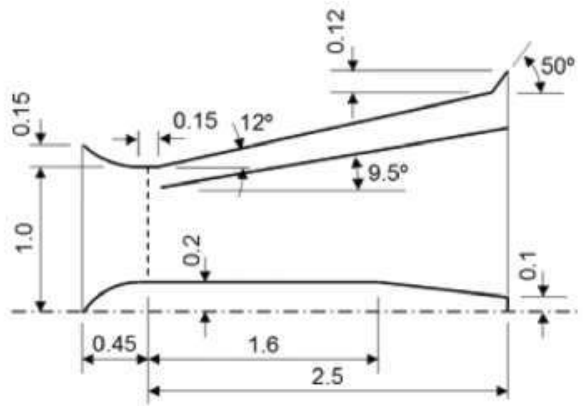

Fig. 13. Sketch of the configurations studied in meters. 


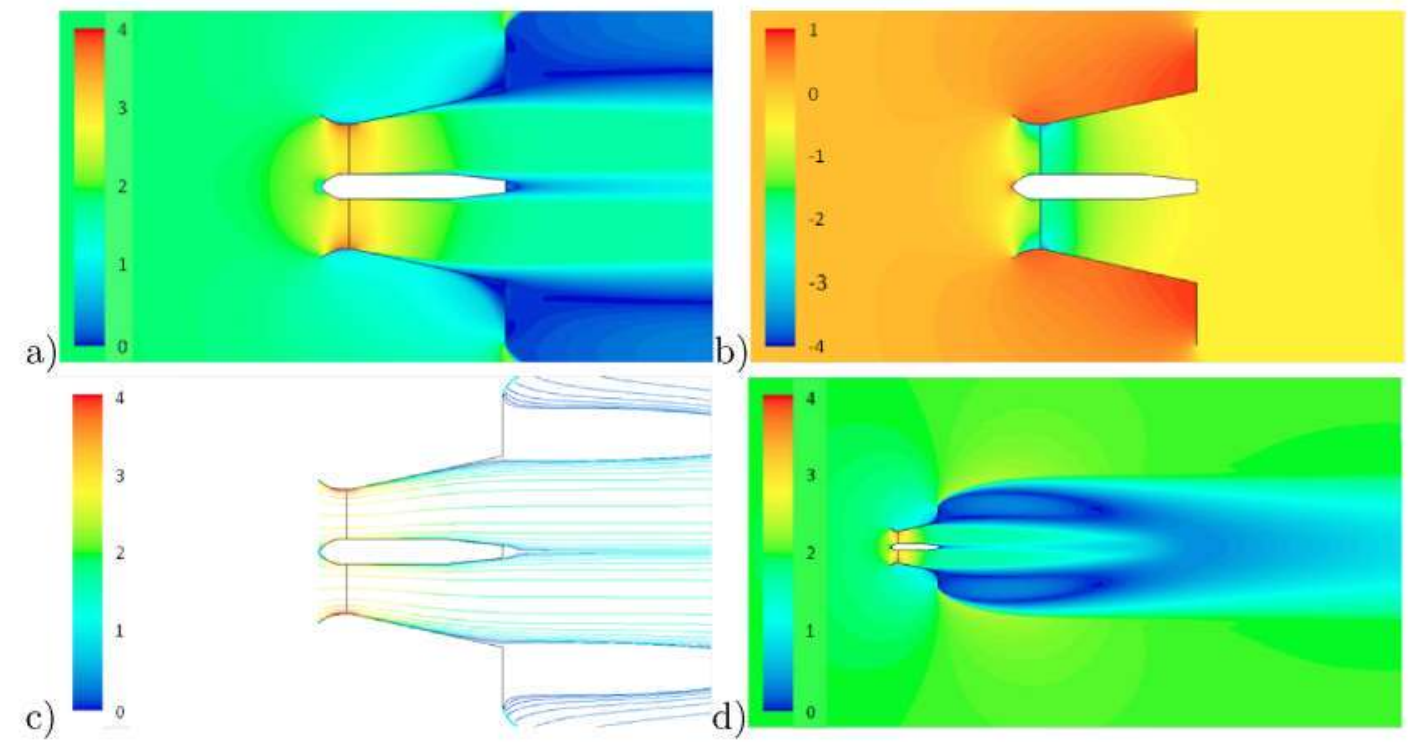

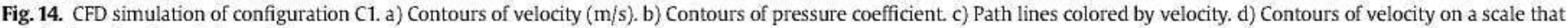
emphasizes the size of the wake.

obtained from CFD is considered, together with a suitable coefficient of diffuser pressure loss $k_{p d}$ (Table 2). In configuration C4, the $k_{p d}$ is the same as the one obtained from CFD; in configurations C1, $\mathrm{C} 2$ and $\mathrm{C} 3$ the value of $k_{p d}$ given by CFD has to be increased by a factor 1.4. One possible explanation for $\mathrm{C} 1$ and $\mathrm{C} 3$ could be that the flow is detached in the diffuser exit, and an additional loss of total pressure should be considered, which does not happen in case $\mathrm{C4}$.

CFD results for configurations $C 1$ to $C 4$ are shown in Figs. 14-17. Concerning C1 in Fig. 14a, a big detachment region at the rear of the flange, generating a huge wake (14d) can be appreciated. This generates a region of even more negative pressure coefficient behind the turbine 14b. Concerning C2 in Fig. 15a, a small detachment region can be appreciated at the rear part of the diffuser, this confirms that this configuration is close to the maximum included angle [25]. The suction region behind the turbine is much smaller than in configuration $\mathrm{C} 3$.
Concerning C3 in Fig. 16a, the detached region in the diffuser has disappeared thanks to the injection of momentum in the boundary layer. The suction region behind the turbine is similar to configuration $\mathrm{C} 1$, but the recirculation bubble behind the hub is slightly bigger. This suggest that higher included angles could be reached with this approach. Concerning C4 in Fig. 17a, a recirculation bubble can be appreciated just behind the Gurney flap. Despite is the same principle as configuration C1, a smaller wake is generated for a similar extracted power using a vane to help the flow to be attached in the diffuser. The suction region behind the turbine is bigger than in the rest of configurations, $\mathrm{C} 1$ to $\mathrm{C} 3$.

For configuration C1 [16] it should be outlined that (Fig. 14d) the width of the far wake diameter is about 4 times the size of the turbine disk ( 16 times the area). The case C4, shown in Fig. 17, is a diffuser optimized for maximum exit area, for the same a)
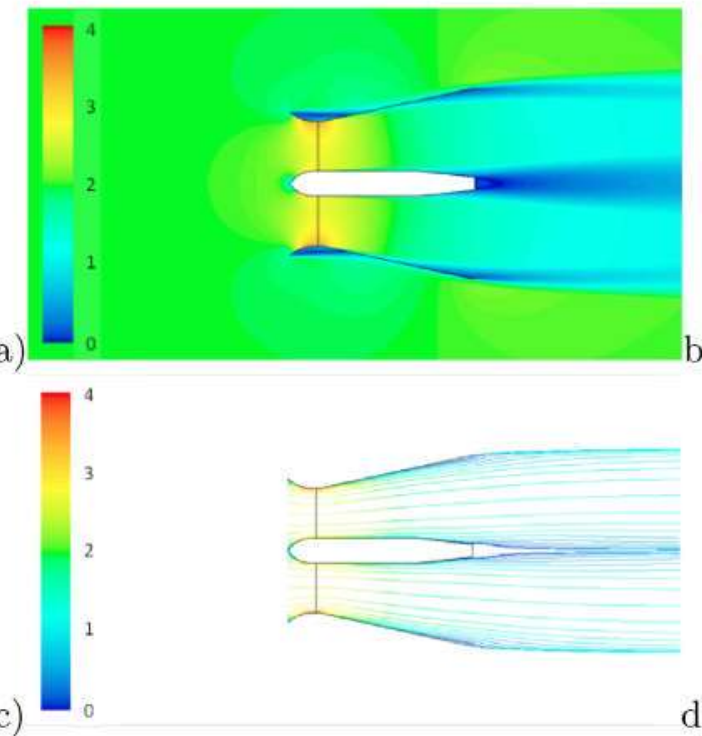

b)
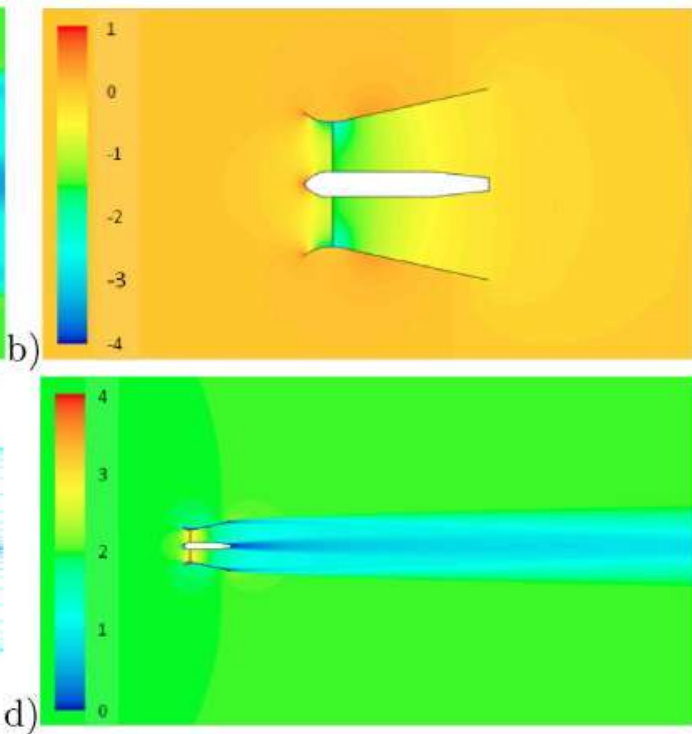

Fig. 15. As Fig. 14 for configuration $\mathrm{C} 2$. 
a)
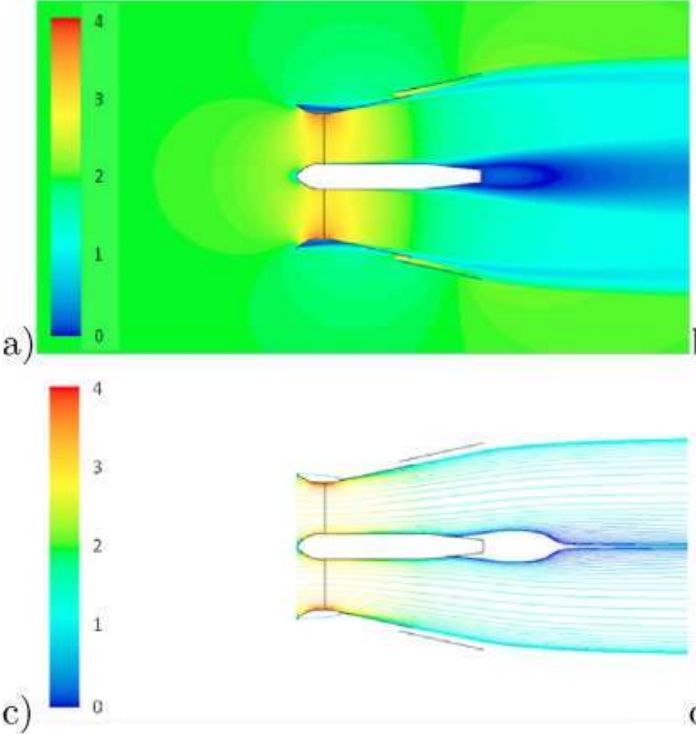

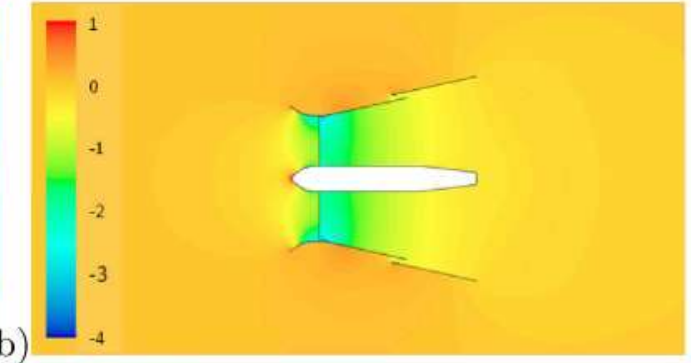

b)

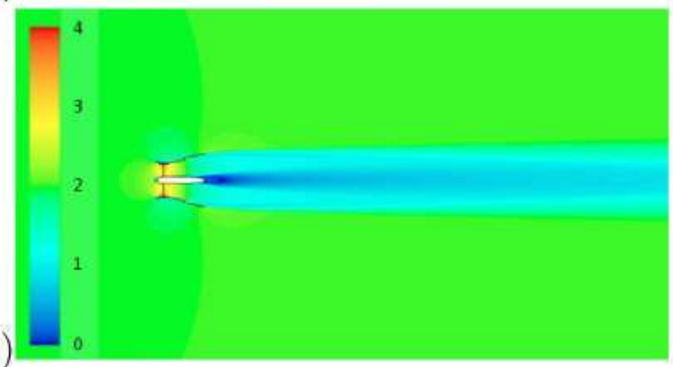

Fig. 16. As Fig. 14 for configuration C3.

values of $A_{c}$ and duct length Abe's SWT. A higher exit area $A_{\text {ex }}$ can not be achieved without causing flow detachment leading to a reduction of $C_{W c}$. This way, a wake much smaller than in configuration $\mathrm{C} 1$ is achieved with a diameter ratio 2.6 (6.7 times the area), one third of the area disturbed by the Abe's flanged turbine, which would allow to introduce more wind turbines in a wind farm.

In the case of the DWAT turbine with the duct developed here (configuration (4) the power coefficient is similar to the configuration $C 1\left(C_{W C}=1.2\right.$ and $C_{W c}=1.25$ respectively), but the relevant issue is the process itself of guiding the CFD modeling with a $1 D$ model for $C_{W c}$ in which the influence of the relevant parameters is included. Some of these parameters are known or easy to obtain $\left(k_{p d}\right)$ but others are only obtained thanks to CFD itself, as $c_{p e x}\left(K_{p c}\right)$ and $k_{p d}$ in detached flow. Once a few points of $c_{p e x}\left(K_{p c}\right)$ are known, the 1D model can be used to interpolate and thus predict the position of the maximum. Once $K_{p c \max }$ is determined, if $A_{e x}$ is a design input, one can estimate $k_{p c}$ from Eq. (2.15) and select the turbine that better suits the pressure jump $k_{p c}$. In other design case, to optimize the duct for a given turbine set, one can obtain the ratio $A_{e x} / A_{c}$ for the $k_{p c}$ of available turbines.

In cases where the size of the wake generated by the DAWT is relevant, is advisable to compare the different designs in terms of extracted power $C_{W c}$ referred to the wake area $A_{\text {wake. }}$. The wake area, $A_{\text {wake }}$, has been determined as the width needed by the flow (at 10 wind turbine diameter distance from the turbine section) to recover the upstream flow speed. The wake area of the different configurations is presented in Table 3.

Configuration $\mathrm{C} 1$ is considerably penalized against the others when referred to the wake area, as shown in Fig. 19. Configuration $\mathrm{C} 4$ shows more than double power density than $\mathrm{C} 1$, meanwhile $\mathrm{C} 2$ and $\mathrm{C} 3$ perturb less the flow generating a power density higher than three times that of $\mathrm{C} 1$. The configuration $\mathrm{C} 4$ would be a)
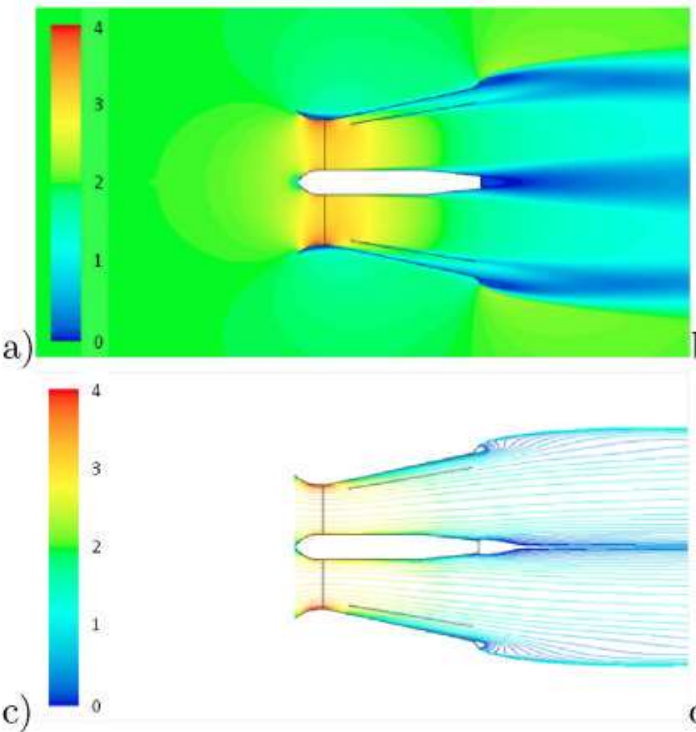

d)
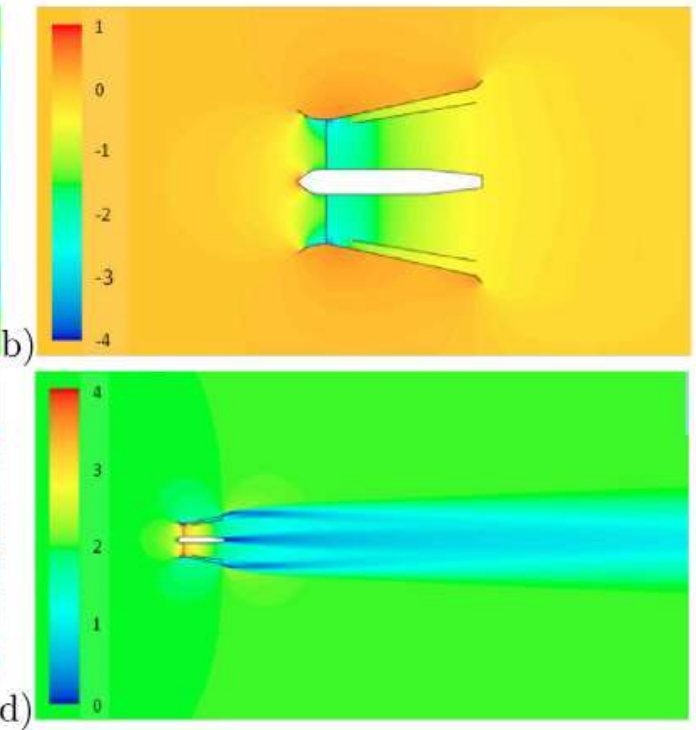

Fig. 17. As Fig. 14 for configuration C4. 


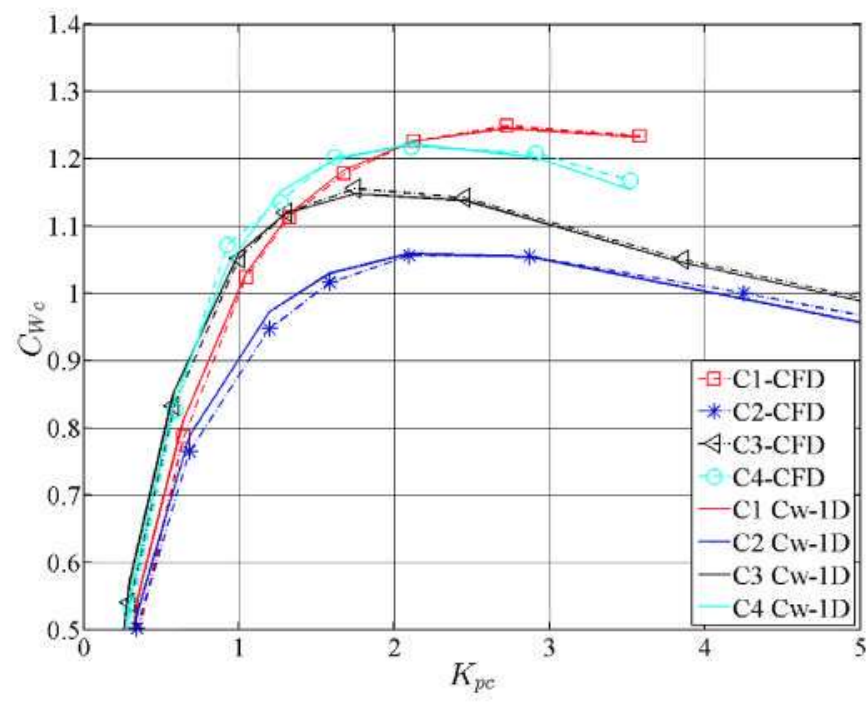

Fig. 18. Variation of power coefficient $C_{W_{c}}$ with the turbine pressure loss $K_{p c}$. Comparison of CFD with $1 \mathrm{D}$ model results for configurations $\mathrm{C} 1$ to $\mathrm{C} 4$.

a compromise between large extracted power and moderated wake perturbation. This is the main reason for proposing this configuration as a possible candidate for DAWT optimization in wind farms or tidal scenarios. An extreme case of configuration C3 can be found in Hjort and Larsen [27], but the complexity of manufacturing and maintenance makes it less economically attractive.

Despite the configuration $\mathrm{C} 3$ extracts less power per wake crosssection area for $K_{p c}>1.5$ than configuration $C 2$ (see Fig. 19), it extracts $10 \%$ more effective power $C_{W C}$ for a similar wake crosssection area (see Fig. 18).

\section{Conclusions}

A study of the design method of an optimized diffuser for a wind turbine based on the actuator disk theory, including the total pressure loss in the diffuser is presented. It has been shown that the proposed method based on a 1D semiempirical model supported by CFD helps on the design process of optimized diffuser for a wind turbine. The 1D analytical model involves the most relevant parameters $\left(k_{p c}, k_{p d}, \mu, c_{p e x}\right)$, some of them can be estimated by different methods. The model allows to predict the main DAWT characteristic performances $\left(\frac{A_{\infty}}{A_{e x}}, \frac{U_{c}}{U_{\infty}}, C_{W c}, C_{W e x}, C_{W e x \max i}, C_{\text {Wex max } r}\right)$ and to compare with the Betz limit. The model also allows to evaluate the design or experimental results, comparing them with the ideal maximum (Fig. 3), and describes the influence of $k_{p d}$ and pressure coefficient $c_{\text {pex }}\left(k_{p c}\right)$ in the power coefficient $C_{W c}$. The total pressure loss in the turbine $k_{p c}$ is one of the key parameters. It controls the flow through the duct and influences the flow in the diffuser. It determines the maximum power in two ways: directly as the pressure jump through the turbine, and indirectly controlling the flow through the duct, together with the pressure losses at the diffuser

Table 3

Results from CFD for the wake area, $A_{\text {wake }}$ of the different DWAT configurations.

\begin{tabular}{lllll}
\hline & $\mathrm{C} 1$ & $\mathrm{C}$ & $\mathrm{C}$ & $\mathrm{C}$ \\
\hline$A_{\text {wake }}\left[\mathrm{m}^{2}\right]$ & 63.9 & 14.1 & 16.3 & 24.6 \\
\hline
\end{tabular}

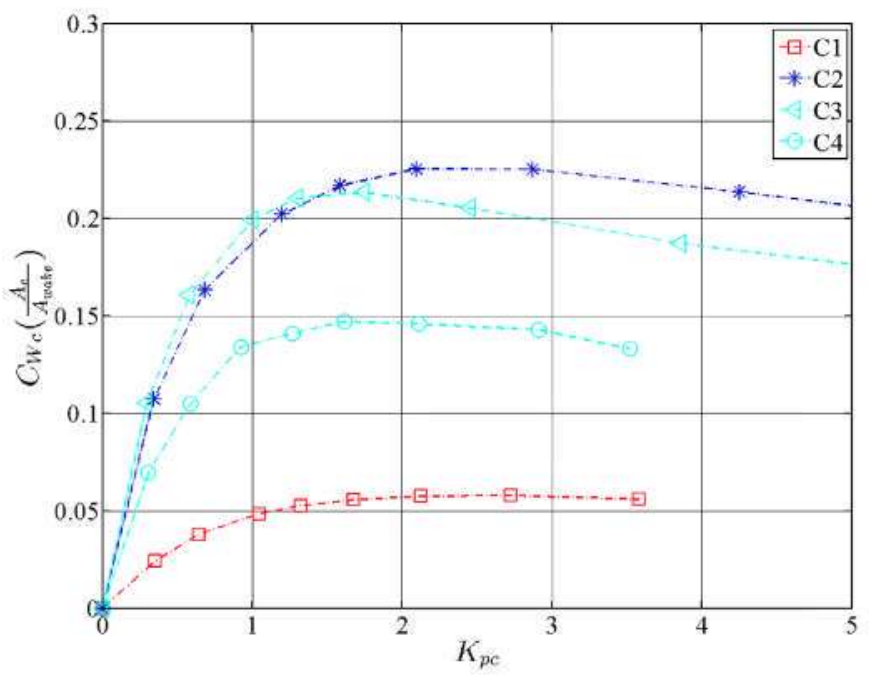

Fig. 19. Variation of power coefficient referred to the wake cross-section area $C_{W c}\left(A_{C}\right.$ $\left(A_{\text {wake }}\right.$ ) as a function of the pressure loss in the turbine $K_{p c}$.

Universal expressions have been established, which are independent of all the parameters, between the power coefficient and the pressure loss at the turbine (or disk loading and the thrust coefficient), that show good agreement with the numerical and experimental results.

The 1D model has also helped to evaluate the performances of the different models (Figs. 5, 18 and 19).

With the conclusions obtained from the 1D model, the design of 3 DAWT models with Fluent has been faced. The numeric model has been validated, and the performance of the 3 developed models has been compared with $\mathrm{C} 1$ from Abe et al. [16]. With a few CFD results, the 1D model can be used to interpolate and find the value of the turbine pressure loss for maximum power extraction. Similar energy extraction from the flow has been reached, with configurations $\mathrm{C} 4$ and $\mathrm{C}$, but $\mathrm{C} 4$ with much smaller wake cross-section area, making this design more suitable for wind farms or tidal applications. The relevance of referring the turbine extracted power to the wake cross section area has been highlighted.

\section{Annex 1. Variation of $c_{p e}\left(K_{p c}\right)$}

The results from numerical simulations have contributed to determine the variation of $c_{p e x}$ with the parameter $K_{p c}$ for different geometries. The SWT data from Abe et al. [16] (C1) and the configuration C4 proposed in this paper are shown in Fig. A.1. For this last case, the variation is almost linear. The data fitting in the proximity of $K_{p c}=2$ gives

$c_{p e x}=c_{p e 0}\left(1+\delta\left(K_{p c}-2\right)\right)$

where $c_{\text {pex } 0}=-0.43$ and $\delta=-0.12$. Increasing the turbine pressure loss $K_{p c}$, decreases the flow rate that passes through the intake, and $c_{\text {pex }}$ gets closer to zero. In Abe et al. [16] (C1) the flange is quite large and $c_{p e x}$ does not vary much with $K_{p c}$, as the change in the flow does not significantly affect $c_{\text {pex. }}$. 


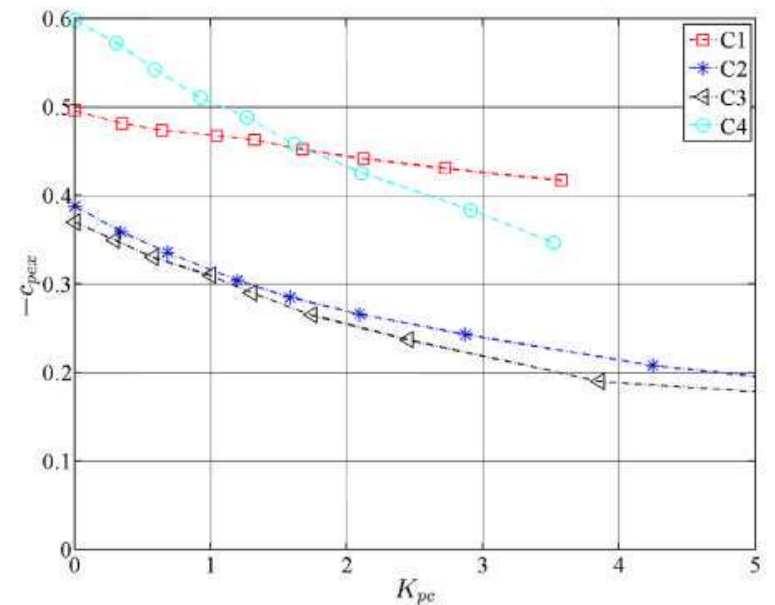

Fig. A.1. Variation of $c_{p e x}$ as a function of the turbine pressure loss coefficient $K_{p c}$ for several configurations ( $\mathrm{C} 1$ to $\mathrm{C} 4)$. Observe that the diffusers without flange ( $\mathrm{C} 2, \mathrm{C} 3$ ) have smaller values of $\left|c_{\text {pex }}\right|$ than the ones with flange or Gurney flap (C1, C4).

\section{References}

[1] M.I. Blanco, The economics of wind energy, Renew. Sustain. Energy Rev. 13 (6-7) (2009) 1372-1382, http://dx.doi.org/10.1016/j.rser.2008.09.004. ISSN 13640321.

[2] L. Neij, Cost development of future technologies for power generation-A study based on experience curves and complementary bottom-up assessments, Energy Policy 36 (6) (2008) 2200-2211, http://dx.doi.org/10.1016/ j.enpol.2008.02.029. ISSN 03014215

[3] N. Goudarzi, W.D. Zhu, A review on the development of wind turbine generators across the world, Int. J. Dyn. Control 1 (2) (2013) 192-202, http:/ dx.doi.org/10.1007/s40435-013-0016-y. ISSN 21952698.

[4] P. Del Rio, A. Calvo Silvosa, G. Iglesias Gomez, Policies and design elements for the repowering of wind farms: a qualitative analysis of different options, Energy Policy 39 (4) (2011) 1897-1908, http://dx.doi.org/10.1016 j.enpol.2010.12.035. ISSN 03014215.

[5] D.G. Phillips, An Investigation on Diffuser Augmented Wind Turbine Design, $\mathrm{PhD}$ thesis, The University of Auckland, 2003.

[6] M.O.L. Hansen, N.N. Sorensen, R.G.J. Flay, Effect of placing a diffuser around a wind turbine, Wind Energy 3 (4) (2000) 207-213, http://dx.doi.org/10.1002/ we.37. ISSN 1095-4244.

[7] C.J. Lawn, Optimization of the power output from ducted, in: Proceedings of the Institution of Mechanical Engineers-Part A- Power \& Energy, vol. 217. 2003, pp. 107-118.

[8] M. Shives, C. Crawford, Developing an empirical model for ducted tidal turbine performance using numerical simulation results, Proc. Inst. Mech. Eng. Part A J. Power Energy 226 (1) (2012) 112-125, http://dx.doi.org/10.1177/ 0957650911417958. ISSN 0957-6509.

[9] B. Kosasih, A. Tondelli, Experimental study of shrouded micro-wind turbine, Proced. Eng. 49 (2012) 92-98, http://dx.doi.org/10.1016/..proeng.2012.10.116. ISSN 18777058.

[10] S.A.H. Jafari, B. Kosasih, Flow analysis of shrouded small wind turbine with a simple frustum diffuser with computational fluid dynamics simulations, J. Wind Eng. Ind. Aerodyn. 125 (2014) 102-110, http://dx.doi.org/10.1016 j.jweia.2013.12.001. ISSN 01676105

[11] J.N. Sørensen, Aerodynamic aspects of wind energy conversion, Annu. Rev. Fluid Mech. 43 (2011) 427-448, http://dx.doi.org/10.1146/annurev-fluid122109-160801. ISSN 0066-4189.

[12] LJ Vermeer, JN. Sørensen, A. Crespo, Wind turbine wake aerodynamics, Prog. Aerosp. Sci. 39 (6-7) (2003) 467-510, http://dx.doi.org/10.1016/503760421(03)00078-2. ISSN 03760421.

[13] P. Mycek, B. Gaurier, G. Germain, G. Pinon, E. Rivoalen, Experimental study of the turbulence intensity effects on marine current turbines behaviour. Part I: one single turbine, Renew. Energy 66 (2014) 729-746, http://dx.doi.org/ 10.1016/j.renene.2013.12.036. ISSN 09601481.

[14] D.A. Howey, A. Bansal, A.S. Holmes, Design and performance of a centimetrescale shrouded wind turbine for energy harvesting, Smart Mater. Struct. 20 (8) (2011) 085021, http://dx.doi.org/10.1088/0964-1726/20/8/085021. ISSN
0964-1726.

[15] K.I. Abe, Y. Ohya, An investigation of flow fields around flanged diffusers using CFD, J. Wind Eng. Ind. Aerodyn. 92 (3-4) (2004) 315-330, http://dx.doi.org/ 10.1016/j.jweia.2003.12.003. ISSN 01676105.

[16] K. Abe, M. Nishida, A. Sakurai, Y. Ohya, H. Kihara, E. Wada, K. Sato, Experimental and numerical investigations of flow fields behind a small wind turbine with a flanged diffuser, J. Wind Eng. Ind. Aerodyn. 93 (12) (2005) 951-970, http://dx.doi.org/10.1016/j.jweia.2005.09.003. ISSN 01676105.

[17] Y. Ohya, T. Karasudani, A. Sakurai, K.I. Abe, M. Inoue, Development of a shrouded wind turbine with a flanged diffuser, J. Wind Eng. Ind. Aerodyn. 96 (5) (2008) 524-539, http://dx.doi.org/10.1016/j.jweia.2008.01.006. ISSN 01676105 .

[18] R. Chaker, M. Kardous, F. Aloui, SB. Nasrallah, Open angle effects on the aerodynamic performances of a flanged Diffuser Augmented Wind Turbine ( DAWT ), in: Conférence Internationale des Energies Renouvelables (CIER13), vol. 2, 2014.

[19] A.C. Aranake, V.K. Lakshminarayan, K. Duraisamy, Computational analysis of shrouded wind turbine configurations using a 3-dimensional RANS solver, Renew. Energy 75 (2015) 818-832, http://dx.doi.org/10.1016/ jrenene. 2014.10.049. ISSN 0960-1481.

[20] Su-Huei Chang, Qi-Hong Lim, Kuo-Hsin Lin, Design of a wind energy capturing device for a vehicle, in: 2014 5th International Conference on Intelligent Systems, Modelling and Simulation, 2014, pp. 435-440, http://dx.doi.org/ 10.1109/1SMS.2014.80

[21] W. Shi, D. Wang, M. Atlar, B. Guo, K.C. Seo, Optimal design of a thin-wall diffuser for performance improvement of a tidal energy system for an AUV, Ocean. Eng. 108 (2015) 1-9, http://dx.doi.org/10.1016/.oceaneng.2015.07.064. ISSN 00298018.

[22] N.W. Cresswell, G.L. Ingram, R.G. Dominy, The impact of diffuser augmentation on a tidal stream turbine, Ocean. Eng. 108 (2015) 155-163, http:/ dx.doi.org/10.1016/j.oceaneng.2015.07.033. ISSN 00298018.

[23] R. Luquet, D. Bellevre, D. Frechou, P. Perdon, P. Guinard, Design and model testing of an optimized ducted marine current turbine, Int. J. Mar. Energy 2 (2013) 61-80, http://dx.doi.org/10.1016/j.jiome.2013.05.009. ISSN 22141669.

[24] T.S. Kannan, S.A. Mutasher, Y.H.K. Lau, Design and flow velocity simulation of diffuser augmented wind turbine using CFD, J. Eng. Sci. Technol. 8 (4) (2013) 372-384.

[25] R.D. Blevins, Applied Fluid Dynamics Handbook. New York, 1984. ISBN 9780442212964 .

[26] S. Hjort, H. Larsen, A multi-element diffuser augmented wind turbine, Energies 7 (2014) 3256-3281, http://dx.doi.org/10.3390/en7053256. ISSN 19961073.

[27] S. Hjort, H. Larsen, Rotor design for diffuser augmented wind turbines, Energies 8 (10) (2015) 10736-10774, http://dx.doi.org/10.3390/en81010736. ISSN 1996-1073.

[28] W.X. Wang, T. Matsubara, J. Hu, S. Odahara, T. Nagai, T. Karasutani, Y. Ohya, Experimental investigation into the influence of the flanged diffuser on the dynamic behavior of CFRP blade of a shrouded wind turbine, Renew. Energy 78 (2015) 386-397, http://dx.doi.org/10.1016/j.renene.2015.01.028. ISSN 09601481 .

[29] D. Küchemann, J. Weber, Aerodynamics of Propulsion, McGraw-Hill, 1953.

[30] J. Seddon, E.L. Goldsmith, Intake Aerodynamics, AIAA Education Series, 1985.

[31] B.L. Gilbert, R.A. Oman, K.M. Foreman, Fluid dynamics of diffuser-augmented wind turbines, Am. Inst. Aeronautics Astronautics 2 (6) (1978) 368-374.

[32] I.E. Idel'chik, M.O. Steinberg, Handbook of Hydraulic Resistance, Begell House, 1996. ISBN: 9781567000740, LCCN: 92027383,790 pages, https://books. google.com.au/books?id=Fvh6i4TipsgC.

[33] K.M. Foreman, B.L. Gilbert, Further Investigations of Diffuser Augmented Wind Turbines Part II - Technical Report, Technical report, 1979.

[34] S.E. Kim, D. Choudhury, B. Patel, Computations of Complex Turbulent Flows Using the Commercial Code Fluent, Springer Netherlands, Dordrecht, 1999, pp. 259-276. ISBN 978-94-011-4724-8.

[35] C. Yan, Methods and Application of Computational Fluid Dynamics. Technical report, Beihang University Press, 2006.

[36] T.H. Shih, W.W. Liou, A. Shabbir, Z, Yang, J. Zhu, A new K-epsilon Eddy viscosity model for high Reynolds number turbulent flows: model development and validation, Comput. Fluids 24 (August) (1995) 227-238, http://dx.doi.org/ 10.1016/0045-7930(94)00032-T. ISSN 00457930.

[37] A. Betz, Das maximum der theoretisch möglichen ausnutzung des windes durch windmotoren, Z. Das. gesamte Turbinenwes. 26 (1920) 307-309.

[38] 1.B. Celik, U. Ghia, P.J. Roache, C.J. Freitas, P.E. Coleman, H., Raad, Procedure for estimation and reporting of uncertainty due to discretization in CFD applications, I. Fluids Eng. 130 (7) (2008) 78001. ISSN 0098-2202.

[39] F.R. Menter, Two-equation Eddy-viscosity Turbulence Models for Engineering Applications, AIAA, 1994, pp. 1598-1605. 